\title{
TOD Parking Demand Models for New Urban Areas in China
}

\author{
Zhenyu Mei *®i), Liang Kong ${ }^{\circledR}$ and Wenchao Zheng * \\ College of Civil Engineering and Architecture, Zhejiang University, Hangzhou 310058, China; \\ 3150100337@zju.edu.cn \\ * Correspondence: meizhenyu@zju.edu.cn (Z.M.); 0006125@fa.zju.edu.cn (W.Z.)
}

Received: 30 August 2020; Accepted: 10 October 2020; Published: 13 October 2020

\begin{abstract}
At present, many new urban areas adopt the transit-oriented development (TOD) exploitation concept to achieve sustainable urban development, accurately predict parking demand under TOD exploitation, determine factors that influence demand, and establish demand models that are essential to the formation of a reasonable traffic structure in the new urban area. The present study aims to establish a scientific and reasonable parking demand model for TOD exploitation in new urban areas. Influencing factors of parking demand in new urban areas under the concept of TOD are determined, and a framework for a parking demand model is constructed. A travel cost measurement model for travel structures at different travel distances is established, considering travel cost as the core element, given that it affects the travel structure at different distances. Finally, taking the Hangzhou Bay New District as an example, the costs of various travel structures under TOD exploitation are calculated, and the reasonable parking demand is calculated. From the perspective of parking management, the concept of TOD is effectively supported.
\end{abstract}

Keywords: TOD exploitation; travel structure; travel cost; parking demand; travel chain

\section{Introduction}

As of the end of 2019, the number of cars in China reached 260 million, of which 207 million cars were private [1], and the parking gaps were more than 200 million. "Difficult parking" has become a "common problem" in many cities in China. The data released by the National Development and Reform Commission also show that the average ratio of cars and parking spaces in large cities and medium/small-sized cities in the country is approximately 1:0.8 and 1:0.5, respectively, and approximately 1:1.3 in developed countries [2]. At present, the "difficult parking" problem [3] in urban built-up areas is mainly concentrated in old communities, except for hospitals and primary and secondary schools, given their particularities. The main reason is that the requirements for construction prior to 2000 were very low, and many old residential areas in the urban center are seriously inadequate for parking-related constructions. For city managers, the most direct approach is to build parking lots. However, the increase in the number of parking spaces is much less than the increase in demand [4]; instead, high parking demand is stimulated. Therefore, finding a development idea for parking consistent with the concept of sustainable development is necessary.

Transit-oriented development (TOD) provides a new idea, that is, a "public transport-oriented" development model for a pedestrian-oriented community with public transport as the hub and comprehensive development $[5,6]$. Urban public transport guided by TOD has great significance for sustainability and social benefits for urban land-use patterns. Firstly, through intensive and multipurpose land development under the guidance of TOD, effective land use can be obtained and a considerable number of land resources can be economized; secondly, TOD encourages residents to switch their travel methods to more low-carbon ones, thus cutting down on quite a lot of pollutive 
emissions. Thirdly, the TOD mode can produce a series of positive feedback benefits, such as a continuously increasing share of urban public transport and a rising investment in public transport year by year [7]. Furthermore, the TOD concept also shows that, usually, the total number of parking spaces should be strictly controlled in the urban center area with heavy traffic to reduce parking demand [8]. Currently, TOD is widely adopted in urban development in China [9-12], and it can be predicted that more and more cities in China will adopt the TOD mode to help with urban development within the following decade [13]; it provides a brand new idea for guiding parking demand research.

Thus, the influencing factors of parking demand in new urban areas under the concept of TOD were analyzed, and a model framework for parking demand in new urban areas was constructed for TOD exploitation. A travel cost measurement model for travel structures at different travel distances was established, considering travel cost as the core element, given that it affects the travel structure at different distances.

Binhai New City, Hangzhou Bay New District, Ningbo, which is the latest city for TOD exploitation, was considered in this study. The rail stations developed by TOD were selected to quantify the parking demand to guide the construction of the parking lot through the TOD concept. They were not intended to satisfy the parking needs of private car owners but of public transport. The parking demand of the new urban area for TOD exploitation was determined to satisfy the requirements of sustainable development of the transportation system through the calculation and calibration of actual parameters, considering the combination of various transportation modes of rail transit, public transportation, bicycles, private cars, and walking.

The remainder of this paper is structured as follows: Section 2 introduces the factors that influence parking demand; Section 3 illustrates travel costs for different single travel modes and travel chains, and establishes a travel structure measurement model at different distances based on travel cost; Section 4 provides a TOD parking demand model that calculates the parking demand of TOD traffic districts; Section 5 takes Binhai New City as a case study to illustrate the positive effect of the TOD mode on reducing parking demands; Section 6 draws the conclusions and emphasizes the advancement of the TOD mode.

\section{Influencing Factors of Parking Demand}

Many factors influence parking demand, such as land development type and density, block layout and road network planning, motor vehicle ownership and travel level, parking management policies and strategies, and public transportation service level [9]. However, TOD, as a new type of land-use mode, has a more profound impact on parking demand. Different from the influencing factors of parking demand considered in the general parking demand analysis, the parking demand of TOD in new urban areas mainly focuses on some TOD function outputs, such as reducing the number of motor vehicles, reducing the share of car travel, shortening the travel distance per capita and travel time per capita of residents, and ultimately achieving low-carbon transportation and green travel [14].

\subsection{Land Development Type and Density}

TOD stimulates the high-density development of the lands around rail transit stations through the construction of rail transit and forms a number of new urban centers mainly for living with complete supporting facilities [15]. Thus, the multipurpose intensive development mode of TOD greatly affects the parking needs of residential, commercial, and official zones.

The land-use density can be explained by the volume ratio, that is, high land-use density indicates high volume ratio, and accordingly, more people or jobs are available. Thus, the generated parking demand is increased. The land-use mode of TOD is not only intensive, but also multipurpose, where each land-use mode or a certain land-use mode (such as residence) affects others. Thus, the proportion of residents traveling within walking distance increases, and the proportion of traveling motor vehicles decreases, thereby reducing the parking demand. 


\subsection{Block Layout and Road Network Planning}

The TOD block layout and road network planning mainly consider that block size affects the street pedestrian environment; they establish a people-oriented, comfortable pedestrian environment [16]. Generally, when the block area is small, the travel distance and travel time are short, thereby reducing car travel in the new urban area and optimizing the urban traffic structure and further reducing parking demand.

\subsection{Motor Vehicle Ownership and Travel Level}

According to the successful experience of domestic and foreign cities, the ratio of total urban parking spaces to motor vehicle ownership should be between 1.15:1 and 1.25:1 [17]. In addition, according to international traffic standards, the reasonable ratio of the number of motor vehicles to parking spaces is 1:1.2 [18]. Therefore, the number of motor vehicles is very important to identifying the total parking demand in the new urban area. The travel level needs to reflect the number of trips per capita on the one hand and the peak hour traffic flow on the other hand; these aspects are positively related to the peak hour parking demand. TOD can reduce parking demand through overall parking demand management strategies and by inducing low-carbon travel methods.

\subsection{Parking Management Policies and Strategies}

The parking management policy represented by parking charging not only affects its parking demand through the function of TOD, but also regulates the total parking demand through direct policy guidance, which has a double impact on the regulation of parking demand [14]. Thus, the cooperation of parking management policies and strategies with TOD helps to effectively reduce parking demand.

\subsection{Public Transportation Service Level (Rail, Bus, and Bus Rapid Transit)}

TOD mode implies a "public" TOD mode. Therefore, if relatively well-developed public transportation is unavailable, then no TOD exists and a healthy urban transportation system cannot be established. Developed public transportation is conducive to the formation of a green, low-carbon transportation travel atmosphere [9]. A healthy urban travel structure is finally formed by using the walkable block layout and road design to reduce the travel of cars, thereby reducing the parking demand.

In the development of new urban areas, estimating the parking demand has always been the key. Travel cost affects the choice of diverse ways to travel [19]. From the perspective of travel costs, travel chain costs of different ways of transportation are established, the distance from rail stations is considered, travel distances are classified, and the exhaustive method is used to analyze existing travel modes or travel chain methods. The costs of different travel chains are converted into different utility functions related to distance, and the travel structure measurement models at different distances can be calculated using the logit model. In accordance with the land-use type of TOD in the new urban area, the travel demand of the new urban area can be obtained through traffic generation and traffic distribution. When combined with the calculated travel distance measurement model at different distances, the number of outgoing or incoming cars is determined. At this time, the source and destination of cars are clarified, thereby laying the foundation for forecasting parking demand. Finally, a parking demand model for the TOD in the new urban area can be obtained, considering the load factor of cars, the turnover rate of different mixed-use land, and other factors. The overall framework of this model is displayed in Figure 1.

Travel cost refers to the sum of the costs that residents need to pay to travel. Travel cost does not only indicate the fare, but also includes time cost and comfort cost. For the convenience of comparison and statistics, costs other than expenses are converted into expenses through the model; they are expressed in monetary units of measure. Before traveling, residents compare the travel costs caused by different travel modes and choose the travel mode with the lowest travel cost. Therefore, travel cost affects parking demand by influencing the travel mode of the traveler. 


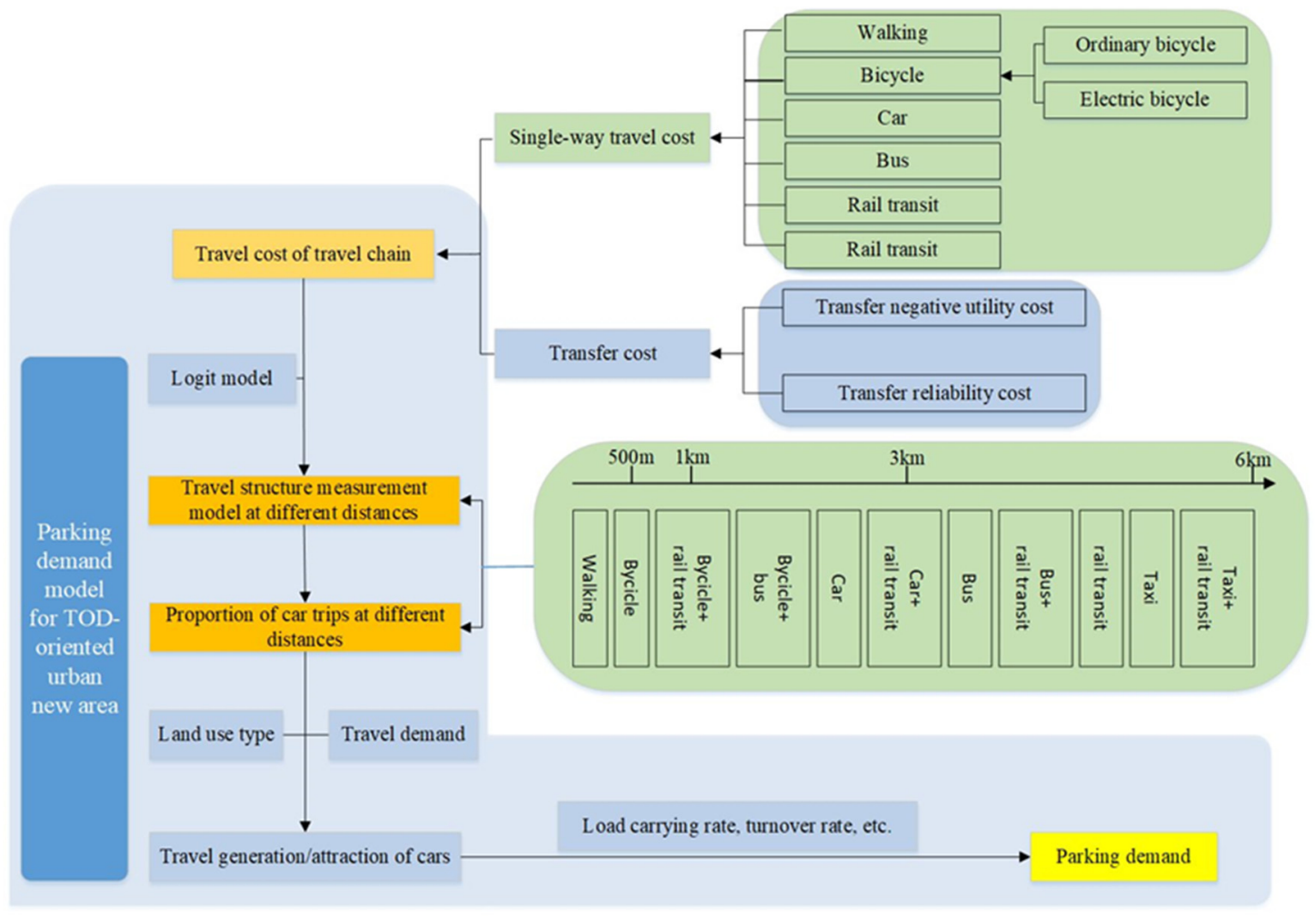

Figure 1. Overall framework of the model. TOD: transit-oriented development.

\section{Travel Structure Measurement Model at Different Distances Based on Travel Cost}

From the perspective of travel costs, under the background of different travel distances, different travel modes have different advantages in travel costs. Obtaining the travel structure at different travel distances is one of the core problems in this study. In the following section, we analyze the relationship between travel structure and travel distance in views of the travel cost of each travel mode.

\subsection{Single-Way Travel Cost Structure}

Generally, in the urban transportation system, travel modes mainly include private car, bus, rail transit, taxi, bicycle (electric bicycle), and walking. Different travel modes have their own characteristics, as follows: in terms of travel distance, walking mode is suitable for short-distance travel, bicycle mode is suitable for short- and medium-distance travel, and bus mode, rail transit mode, and private car mode are suitable for medium- and long-distance travels. Ye Ying established a travel mode chain cost measurement model by analyzing the cost structure and transfer cost of a single travel mode [20]. Apart from the direct costs of different travel modes, external costs include air pollution, noise pollution, congestion, and traffic accidents. This part of the cost is difficult to quantify and is considered from the perspective of government managers; thus, it can be applied to government policy management [21]. However, this study mainly focuses on travelers' decisions; thus, external costs can be ignored.

Single-way travel costs only include travel costs and travel-aware time costs, excluding negative transfer utility costs and transfer reliability costs. In a single-way trip, in addition to the necessary travel fare, the travel cost includes travel time cost, walking time and waiting time cost, time reliability cost, and vehicle congestion cost. These costs are related to the travel time value. Thus, they are 
collectively referred to as time costs, that is, travel-aware time costs. Therefore, single-way travel cost is the sum of travel fare and travel-aware time costs, as shown in the following formula:

$$
T C_{i}=T F_{i}+T T_{i}=\sum_{j} D_{i j} T F_{i j}+\sum_{k} d_{i k} T T_{i k}
$$

where $T F_{i}$ is the travel fare cost of the $i$ th travel mode; $T F_{i j}$ is the $j$ th type of travel fare of the $i$ th travel mode. $J=1-8$ represents vehicle depreciation costs, insurance costs, maintenance costs, electricity consumption costs, ticket fees, fuel consumption, parking fees, and taxi fees; $D_{i j}$ is a dummy variable of the $j$ th type of the travel fare of the $i$ th travel mode. When the $i$ th travel mode includes the $j$ th type of travel fare, then $D_{i j}=1$; otherwise, $D_{i j}=0 . T T_{i}$ is the time cost of the $i$ th travel mode; $T T_{i k}$ is the $k$ th type of time cost of the $i$ th travel mode. $\mathrm{K}=1-5 ; d_{i k}$ is a dummy variable of the $k$ th type of time cost of the $i$ th travel mode. When the ith travel mode includes the $k$ th type of time cost, then $d_{i k}=1$; otherwise, $d_{i k}=0$. The unit of the travel cost is the yuan.

The travel cost model for each travel mode is listed in Table 1.

Table 1. Travel cost model for each travel mode.

\begin{tabular}{|c|c|c|}
\hline Travel Mode & Cost Structure & Cost Model \\
\hline Walking & Travel time cost & $T T_{t r}$ \\
\hline Bicycle & $\begin{array}{l}\text { Depreciation cost }+ \text { maintenance } \\
\text { cost }+ \text { travel time cost }\end{array}$ & $T F_{d}+T F_{m}+T T_{t r}$ \\
\hline Electric bicycle & $\begin{array}{l}\text { Depreciation cost }+ \text { maintenance } \\
\text { cost }+ \text { travel time cost }+ \text { power } \\
\text { consumption cost }\end{array}$ & $T F_{d}+T F_{m}+T F_{e}+T T_{t r}$ \\
\hline Bus & $\begin{array}{l}\text { Ticket fee }+ \text { travel time cost }+ \\
\text { walking cost }+ \text { waiting cost }+ \\
\text { congestion cost }+ \text { reliability cost }\end{array}$ & $\begin{array}{c}T F_{t}+T T_{t r}+T T_{\text {walk }}+T T_{\text {wait }}+ \\
T T_{c r}+T T_{r}\end{array}$ \\
\hline Rail transit & $\begin{array}{l}\text { Ticket fee }+ \text { travel time cost }+ \\
\text { walking cost }+ \text { waiting cost }+ \\
\text { congestion cost }\end{array}$ & $T F_{t}+T T_{t r}+T T_{\text {walk }}+T T_{\text {wait }}+T T_{r}$ \\
\hline Car & $\begin{array}{l}\text { Depreciation cost }+ \text { insurance cost } \\
+ \text { maintenance cost }+ \text { fuel cost }+ \\
\text { parking cost }+ \text { travel time cost }+ \\
\text { reliability cost }\end{array}$ & $\begin{array}{c}T F_{d}+T F_{i n}+T F_{m}+T F_{f}+T F_{p}+ \\
T T_{t r}+T T_{r}\end{array}$ \\
\hline Taxi & $\begin{array}{l}\text { Taxi fare }+ \text { travel time cost }+ \\
\text { waiting cost }+ \text { reliability cost }\end{array}$ & $T F_{t}+T T_{t r}+T T_{\text {wait }}+T T_{r}$ \\
\hline
\end{tabular}

\subsubsection{Travel Cost for Walking}

As a type of pure physical transportation, walking acts as the most basic and green travel mode. According to domestic urban residents' travel surveys, the travel distance range of pedestrian travel is within $1 \mathrm{~km}$ [22]. Studies have shown that when the walking distance is above $1 \mathrm{~km}$, the acceptance of residents drops rapidly and becomes 0 at $3 \mathrm{~km}$. The main cost of walking is the travel time cost, and its calculation formula is as follows:

$$
\begin{gathered}
T C_{w}=T T_{t r}=\frac{k_{1} \times l^{n_{1}}}{\bar{v}} \times P_{v 0} \\
P_{v 0}=\frac{G D P}{P \times T}
\end{gathered}
$$

where $T C_{w}$ is the travel cost of walking; $T T_{t r}$ is the travel time cost of walking; $l$ is the length of the road section, $\mathrm{km} ; \bar{v}$ is the average speed of the $i$ th travel mode, $\mathrm{km} / \mathrm{h} ; k_{1}$ and $n_{1}$ are coefficients, where $n_{1}$ is generally greater than or equal to $l$, the value of which is set to 1 to simplify the calculation; $P_{v 0}$ is the travel time value, which is the quantitative indicator of all the time values in this study, $y u a n / h$. In China, $P_{v 0}$ is 56 yuan/h (about $8 \mathrm{USD} / \mathrm{h}$ ) according to the data of the year 2019; GDP refers to gross 
national product, yuan; $P$ refers to the annual average employment; $T$ refers to the personal annual average working hours, hour. The travel time value $P_{v 0}$ is calculated using the production method [23].

\subsubsection{Travel Cost for Bicycle}

Bicycle travel is a semi-motorized transportation. Bicycle travel has considerable travel advantages and time advantages due to the characteristics of China's mixed transportation. Generally, the dominant travel range of bicycle travel is within $6 \mathrm{~km}$ [24], especially the travel distance of 3-4 km, where physical and time consumptions are affordable for bicycles. In addition to travel time cost, bicycle travel cost includes depreciation cost and maintenance cost. The calculation formula is as follows:

$$
T C_{b}=T F_{d}+T F_{m}+T T_{t r}=\frac{k_{2} \times l^{n_{2}}}{\bar{v}} \times P_{v 0}+\varepsilon_{1}
$$

where $T C_{b}$ is the travel cost for bicycle, $T T_{t r}$ is the travel time cost for bicycle, $T F_{d}+T F_{m}=\varepsilon_{1}$, $\varepsilon_{1}$ indicates that the depreciation cost and maintenance cost of a single bicycle trip tend to $0 . n_{1} \geq n_{2}$, where $n_{2}$ is also set to 1 .

\subsubsection{Travel Cost for Electric Bicycle}

Compared with ordinary bicycles, the travel cost of electric bicycles, in addition to depreciation cost, maintenance cost, and travel time cost, includes electricity consumption cost. The calculation formula is as follows:

$$
T C_{e}=T F_{d}+T F_{m}+T F_{e}+T T_{t r}=\frac{k \times l}{\bar{v}} \times P_{v 0}+\varepsilon_{2}
$$

where $T C_{e}$ is the travel cost for electric bicycle; $T F_{d}+T F_{m}+T F_{e}=\varepsilon_{2}, \varepsilon_{2}$ indicates that the depreciation cost, maintenance cost, and electricity consumption cost of a single bicycle trip tend to $0 ; k$ is a coefficient.

\subsubsection{Travel Cost for Car}

Private car travel is a form of motorized transportation, whose dominant travel distance range is concentrated above $6 \mathrm{~km}$. Its travel costs include depreciation cost, insurance cost, maintenance cost, fuel cost, parking cost, travel time cost, and reliability cost. Thus, private car travel is the travel mode with the highest cost within a certain distance. That is, the large number of private cars that travel during peak hours is the root cause of urban road traffic congestion. To reduce the travel demand of cars during peak periods, continuously increasing the travel cost of private cars, it is necessary to switch them to other travel modes with lower travel costs or green and low-carbon travel modes. Therefore, the analysis of the travel cost for cars is essential to solve urban traffic congestion. The calculation methods are as follows:

1. The depreciation cost of a single car trip is obtained as follows:

$$
T F_{d}=\frac{V_{n}-V_{r}}{n \times L} \times l
$$

where $L$ is the average annual mileage, $\mathrm{km} ; l$ is the travel distance of a single trip, $\mathrm{km} . V_{n}$ is the original value of the vehicle, including the vehicle's own value and purchase tax; $V_{n}$ is the residual value at the time of being scrapped, generally between $2 \%$ and $10 \% ; n$ is the service life of the vehicle.

2. The insurance cost of a single car trip is obtained as follows:

$$
T F_{i n}=\frac{C}{52 \times q}
$$

where $C$ is the insurance fee paid annually; $q$ is the average number of car uses per week. 
3. The average maintenance cost of a single car trip is as follows:

$$
T F_{m}=P C \times V_{n} \times \frac{l}{1000} \times e \times k \times \exp (f \times I R I) \times C K M^{K_{p}}
$$

where $P C$ is the ratio of the maintenance cost after a thousand kilometer drive to the price of a new car at that time; $e$ and $f$ are the regression coefficients of the model; $k$ is the coefficient of maintenance cost; $K_{p}$ is the vehicle age index or vehicle aging coefficient; IRI is the road smoothness index; $C K M$ is the cumulative mileage of the vehicle.

4. The fuel cost of a single car trip is obtained as follows:

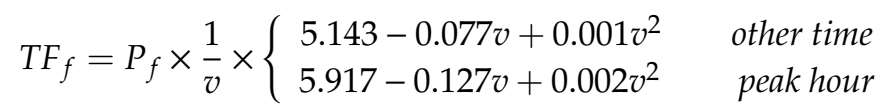

where $v$ is the vehicle speed, $\mathrm{km} / \mathrm{h} ; P_{f}$ is the current price of fuel, yuan/L.

5. The parking cost of a single car trip is obtained as follows:

$$
T F_{p}=C_{p} \times t_{p}
$$

where $C_{p}$ is the price for parking, yuan/h; $t_{p}$ is the total parking time, $\mathrm{h}$.

6. The travel time cost of a single car trip is affected by the road traffic status. The travel time is related to the traffic flow of the road network. The calculation formula is as follows:

$$
\mathrm{TT}_{\mathrm{tr}}=\sum_{a} t_{a}(t) P_{v 0}
$$

where $\sum_{a} t_{a}(t)$ is the total travel time of each section of the travel route, $\mathrm{h}$.

7. Time reliability is the probability that travel demand (OD) pairs can arrive at a specified time under certain traffic demand characteristics. It mainly explores the fluctuation of travel time from the perspective of travelers [25]. According to research, the reliability cost of a single car trip is $1.77 P_{v 0} \sigma$.

Thus, according to Formulas (6)-(11), the total cost of a single car trip can be calculated as follows:

$$
\begin{gathered}
T C_{c}=T F_{d}+T F_{i n}+T F_{m}+T F_{f}+T F_{p}+T T_{t r}=\frac{V_{n}-V_{r}}{n \times L} \times l+\frac{C}{52 \times q} \\
+P_{f} \times \frac{1}{v}\left\{\left\{\begin{array}{ll}
5.143-0.077 v+0.001 v^{2} & \text { other time } \\
5.917-0.127 v+0.002 v^{2} & \text { peak hour }
\end{array}\right\}+C_{p} \times t_{p}\right. \\
+P C \times V_{n} \times \frac{l}{1000} \times e \times k \times \exp (f \times I R I) \times C K M^{K_{p}}+\sum_{a} t_{a}(t) P_{v 0}+1.77 P_{v 0} \sigma
\end{gathered}
$$

\subsubsection{Travel Cost for Bus}

The bus is also a form of motor vehicle transportation, for which the travel cost structure is relatively complicated, covering travel time cost, walking cost, waiting cost, and reliability cost as well as bus fare and on-bus crowding cost. According to data surveys of major cities across the country, bus fare is normally two yuan, and travel time cost and reliability cost are calculated in the same ways as those for cars. In addition, according to foreign studies, the walking cost and waiting time cost of the bus are 1.5 times the time value [26]. Here, we only calculate the crowding cost of the bus. Crowding cost is mainly related to the full load rate of the bus. The calculation formula is as follows:

$$
T F_{c r}= \begin{cases}0 & 0 \leq L F \leq 0.8 \\ \sum_{a} t_{a}(t) 0.55(L F-0.8) e^{-0.074(L F-0.8)^{2}} P_{v 0} & L F>0.8\end{cases}
$$

where $L F$ is the full load rate of the bus. 
Thus, on the basis of these calculation results, the total travel cost for the bus can be added as follows:

$$
\begin{gathered}
T C_{b}=T F_{t}+T F_{t r}+T F_{\text {walk }}+T F_{\text {wait }}+T F_{c r}+T F_{r}=2 \sum_{a} t_{a}(t) P_{v 0}+1.5 P_{v 0} t_{\text {walk }} \\
+1.5 P_{v 0} t_{\text {wait }}+\left\{\begin{array}{ll}
0 & 0 \leq L F \leq 0.8 \\
\sum_{a} t_{a}(t) 0.55(L F-0.8) e^{-0.074(L F-0.8)^{2}} P_{v 0} & L F>0.8
\end{array}+1.77 P_{v 0} \sigma\right.
\end{gathered}
$$

\subsubsection{Travel Cost for Rail Transit}

Rail transit is a green and low-carbon mode of transportation. Compared with the bus, rail transit has attracted much attention as resident travel because of its large capacity and high on-time rate [27]. Its travel cost structure is similar to the bus, including rail fare, travel time cost, walking cost, waiting cost, and crowding cost. In most domestic charging modes of urban rail transit, except the implementation of the two-yuan full ticket system in Beijing before 2014, a segmented fare related to travel distance is currently used. The Ningbo subway toll standard is used to perform the relevant calculation. The calculation method of travel time cost is the same as that for walking and bicycle on the basis of the ratio of travel distance to driving speed. The congestion cost of a single rail transit can be ignored. Therefore, the calculation formula for the travel cost for rail transit is as follows:

$$
\begin{aligned}
& T C_{r}=T F_{t}+T F_{t r}+T F_{\text {walk }}+T F_{\text {wait }}+T F_{r} \\
& =\left\{\begin{array}{l}
{[l / 4]+1 \quad l \leq 12 k m} \\
{[l / 6]+2 \quad l \leq 24 k m} \\
{[l / 8]+3 \quad l>24 k m}
\end{array}+\sum_{a} t_{a}(t) P_{v 0}+1.5 P_{v 0} t_{\text {walk }}+1.5 P_{v 0} t_{\text {wait }}\right.
\end{aligned}
$$

\subsubsection{Travel Cost for Taxi}

Taxi is also a form of motor vehicle transportation, and its travel cost is relatively high and mainly concentrated in the taxi fare. When the traffic is congested, the travel time cost tends to be equal to the travel time cost of the bus. The travel cost for the taxi mainly includes taxi fare, travel time cost, waiting cost, and reliability cost.

The travel cost for the taxi is related to the travel distance. Here, we adopt the "Opinions on Deepening the Reform of the Taxi Industry in Ningbo City," formally promulgated and implemented by the Ningbo Municipal Government on 1 March 2016, that is, to adjust the taxi price from the original starting price of 10 yuan per three kilometers to 11 yuan per three kilometers, and the original unit price of 2-2.4 yuan per kilometer. The calculation method for travel time cost is the same as that for car, and the calculation methods for waiting cost and reliability cost are also in accordance with that for car. Therefore, the travel cost of the taxi is as follows:

$$
\begin{gathered}
T C_{\text {taxi }}=T F_{t}+T F_{t r}+T F_{\text {walk }}+T F_{r} \\
=\left\{\begin{array}{ll}
{\left[11+2.4 T_{c} / 4\right]+1} & l \leq 3 \\
{\left[2.5 l+3.5+2.4 T_{c} / 4\right]} & l \leq 10 \\
{\left[3.75 l-9+2.4 T_{c} / 4\right]} & l>10
\end{array}+\sum_{a} t_{a}(t) P_{v 0}+1.5 P_{v 0} t_{\text {wait }}+1.77 P_{v 0} \sigma\right.
\end{gathered}
$$

\subsection{Travel Chain Cost Structure}

According to the travel chain cost calculation method proposed by Ye Ying, the travel mode chain cost is composed of the cost of the single travel mode and its transfer cost [20]. In addition, according to the definition of the travel mode chain, assuming that one trip has $\mathrm{n}$ travel modes, including $(\mathrm{n}-1)$ times of transfer, the cost estimation model of the travel mode chain is shown in the following formula:

$$
\begin{gathered}
T C_{\text {chain }}=\sum_{i=1}^{n} T C_{i}+(n-1) \overline{W T P} \times P_{v 0}+\sum_{i=1}^{n-1} T_{w}^{i} \times P_{v, \text { walk }}+\sum_{i=1}^{n-1} T_{i n}^{i} \times P_{v, \text { wait }} \\
+\sum_{i=1}^{n-1} \sigma_{i} \times P_{v, r e}
\end{gathered}
$$


where $T C_{i}$ is the travel cost for the $i$ th travel mode in the travel mode chain, yuan; $\overline{W T P}$ is the value of willingness to pay for the "negative utility" of transfer, hour; $T_{w}^{i}, T_{i n^{\prime}}^{i}$, and $\sigma_{i}$ are the walking time, waiting time, and standard deviation, respectively, of the waiting time of the transfer for the $i$ th travel mode to the next travel mode in the travel mode chain, hour; $P_{v 0}, P_{v, \text { walk }}, P_{v, \text { wait }}$, and $P_{v, \text { re }}$ are the corresponding time values, yuan/h.

A trip may have only one or multiple travel modes. Thus, to simplify the model, the travel chain cost structure mainly considers two situations. The first is that only one travel mode exists, and the second is that only one transfer is considered, that is, two travel modes are available.

In addition, because the travel costs of bicycle and electric bicycle are relatively close, they can be reduced to one category, collectively called bicycle.

Considering that the difference in travel distance leads to changes in travel structure, when traveling in a single way, as the travel distance changes, some transportation mode becomes invalid. For example, the dominant travel range of walking is within $1 \mathrm{~km}$. When it exceeds $3 \mathrm{~km}$, few people choose to walk. The dominant travel range of the bicycle is between 3 and $4 \mathrm{~km}$. Similarly, once it exceeds $6 \mathrm{~km}$, few people choose to travel by bicycle. The distance between stations of rail transit is generally approximately $2 \mathrm{~km}$. Thus, no rail transit exists within $1 \mathrm{~km}$. Similarly, other invalid travel modes can be inferred. In a single transfer, if the bicycle travel distance is less than $500 \mathrm{~m}$, then walking is selected, and bus or rail stations are generally within $1 \mathrm{~km}$. Therefore, the travel distance is between $500 \mathrm{~m}$ and $1 \mathrm{~km}$ when traveling by bicycle. Similarly, the transfer distance of car travel and taxi travel should be between 1 and $3 \mathrm{~km}$. Table 2 shows the travel chain divided according to travel distance.

Table 2. Division of the travel chain.

\begin{tabular}{|c|c|c|c|c|c|}
\hline Travel Chain & $0-500 \mathrm{~m}$ & $500 \mathrm{~m}-1 \mathrm{~km}$ & $1-3 \mathrm{~km}$ & $3-6 \mathrm{~km}$ & Above $6 \mathrm{~km}$ \\
\hline Walking & $\sqrt{1}$ & $\sqrt{ }$ & $\sqrt{ }$ & -2 & - \\
\hline Bicycle & $\sqrt{ }$ & $\sqrt{ }$ & $\sqrt{ }$ & $\sqrt{ }$ & - \\
\hline Bicycle + rail transit & - & - & - & $\sqrt{ }$ & $\sqrt{ }$ \\
\hline Bicycle + bus & - & - & - & $\sqrt{ }$ & $\sqrt{ }$ \\
\hline Car & - & $\sqrt{ }$ & $\sqrt{ }$ & $\sqrt{ }$ & $\sqrt{ }$ \\
\hline Car + rail transit & - & - & - & - & $\sqrt{ }$ \\
\hline Bus & - & $\sqrt{ }$ & $\sqrt{ }$ & $\sqrt{ }$ & $\sqrt{ }$ \\
\hline Bus + rail transit & - & - & - & $\sqrt{ }$ & $\sqrt{ }$ \\
\hline Rail transit & - & - & $\sqrt{ }$ & $\sqrt{ }$ & $\sqrt{ }$ \\
\hline Taxi & - & $\sqrt{ }$ & $\sqrt{ }$ & $\sqrt{ }$ & $\sqrt{ }$ \\
\hline Taxi + rail transit & - & - & - & - & $\sqrt{ }$ \\
\hline
\end{tabular}

${ }^{1} \sqrt{ }$ indicates that the mode of transportation was chosen. ${ }^{2}-$ indicates that the mode of transportation was not chosen.

The table shows that as the travel distance changes, the structure of the travel mode begins to change. At the beginning, only two transportation modes are available when the travel distance is within $500 \mathrm{~m}$, and nine transportation modes when the travel distance is above $6 \mathrm{~km}$. After substituting the travel cost of each transportation mode into Table 2, we obtain Table 3. The travel chain cost includes transfer cost, which is represented by $w$. The transfer cost is composed of the transfer negative utility cost and the transfer reliability cost, that is, the transfer walking time cost, waiting time cost, and waiting time standard deviation cost. Thus, the calculation formula of the transfer cost under the condition of a single transfer is as follows:

$$
w=T_{w} \times P_{v, w a l k}+T_{i n} \times P_{v, w a i t}+\sigma \times P_{v, r e}
$$


Table 3. Structure of the travel chain cost.

\begin{tabular}{cccccc}
\hline Travel Chain & $\mathbf{0 - 5 0 0 ~} \mathbf{~}$ & $\mathbf{5 0 0} \mathbf{~} \mathbf{- 1} \mathbf{~ k m}$ & $\mathbf{1 - 3} \mathbf{~ k m}$ & $\mathbf{3 - 6} \mathbf{~ k m}$ & Above $\mathbf{6} \mathbf{~ k m}$ \\
\hline Walking & $T C_{w}$ & $T C_{w}$ & $T C_{w}$ & - & - \\
Bicycle & $T C_{b}$ & $T C_{b}$ & $T C_{b}$ & $T C_{b}$ & - \\
Bicycle + rail transit & - & - & - & $T C_{b}+T C_{r}+\omega$ & $T C_{b}+T C_{r}+\omega$ \\
Bicycle + bus & - & - & - & $T C_{b}+T C_{b u s}+\omega$ & $T C_{b}+T C_{t}+\omega$ \\
Car & - & $T C_{c}$ & $T C_{c}$ & $T C_{c}$ & $T C_{c}$ \\
Car + rail transit & - & - & - & - & $T C_{c}+T C_{r}+\omega$ \\
Bus & - & $T C_{b u s}$ & $T C_{b u s}$ & $T C_{b u s}$ & $T C_{b u s}$ \\
Bus + rail transit & - & - & - & $T C_{b u s}+T C_{r}+\omega$ & $T C_{b u s}+T C_{r}+\omega$ \\
Rail transit & - & - & $T C_{r}$ & $T C_{r}$ & $T C_{r}$ \\
Taxi & - & $T C_{\text {taxi }}$ & $T C_{\text {taxi }}$ & $T C_{\text {taxi }}$ & $T C_{\text {taxi }}+T C_{r}+\omega$ \\
Taxi + rail transit & - & - & - & - &
\end{tabular}

Therefore, the cost model of the travel mode chain under the condition of a single transfer is as follows:

$$
T C_{\text {chain }}=\sum_{i=1}^{2} T C_{i}+\overline{W T P} \times P_{v 0}+T_{w} \times P_{v, \text { walk }}+T_{\text {in }} \times P_{v, \text { wait }}+\sigma \times P_{v, r e}
$$

In Formula (19), the travel cost for each travel mode and the negative utility cost caused by the transfer are unavoidable, and the walking time, waiting time, and standard deviation of the waiting time during the transfer process can be 0 .

\subsection{Travel Structure}

Travelers always choose a travel mode with lower travel cost. At this time, the choice of travel mode is a question of selecting the most effective one from multiple choices. Under the condition of logit application, the probability of choosing a certain travel mode is as follows:

$$
P(k)=\frac{\exp \left[-\theta \times \frac{t(k)}{\bar{t}}\right]}{\sum_{i=1}^{m} \exp \left[-\theta \times \frac{t(i)}{\bar{t}}\right]}
$$

where $P(k)$ is the probability of the traveler choosing the $k$ th travel mode; $t(k)$ is the travel cost for the $k$ th travel mode; $\bar{t}$ is the average travel cost of all the travel modes; $\theta$ is a dimensionless parameter; $m$ is the number of travel modes.

According to the structure of the travel chain cost, the travel modes are 2, 5, 6, 8, and 9 at five different distances. Thus, this formula can be converted into the following:

$$
P(i)=\frac{\exp \left[-\theta \times \frac{T C_{i}(l)}{\overline{T C}}\right]}{\sum_{i=1}^{m} \exp \left[-\theta \times \frac{T C_{i}(l)}{T C}\right]}, \quad m=2,5,6,8,9
$$

The travel distance is divided by four distance points of $500 \mathrm{~m}, 1$, 3, and $6 \mathrm{~km}$ into five distance intervals. The travel structures are different because the travel costs and travel mode chains at different travel distances are different. We only need to focus on the proportion of car trips because we want to 
obtain the parking demand. Formula (21) shows that the proportion of car trips from cell $i$ to cell $j P_{c}^{e}(l)$ can be obtained. $P_{c}^{e}(l)$ is exactly $\alpha_{i j}$, whose expression formula is as follows:

$$
\alpha_{i j}=P_{c}^{e}(l)=\left\{\begin{array}{l}
0, \quad l<500 m \\
P_{c}^{1}(l), \quad 500 m \leq l<1 k m \\
P_{c}^{2}(l), \quad 1 k m \leq l<3 k m \\
P_{c}^{3}(l), \quad 3 k m \leq l<6 k m \\
P_{c}^{4}(l), \quad l \geq 6 k m
\end{array}\right.
$$

where $\alpha_{i j}$ represents the proportion of car trips from cell $i$ to cell $j$, which is related to the travel distance $l$.

Substituting Formula (21), the proportions of the car trips within each travel distance range, namely, $p_{C}^{1}(l), p_{C}^{2}(l), p_{C}^{3}(l)$, and $p_{C}^{4}(l)$, can be obtained. The results are as follows:

$$
\begin{aligned}
& P_{c}^{1}(l)=\frac{\exp \left[-\theta \times \frac{T C_{c a r}^{1}(l)}{T C^{1}}\right]}{\sum_{i=1}^{5} \exp \left[-\theta \times \frac{T C_{c a r}^{1}(l)}{T C^{1}}\right]} \\
& P_{c}^{2}(l)=\frac{\exp \left[-\theta \times \frac{T C_{c a r}^{2}(l)}{T C^{2}}\right]}{\sum_{i=1}^{6} \exp \left[-\theta \times \frac{T C_{c a r}^{2}(l)}{T C^{2}}\right]} \\
& P_{c}^{3}(l)=\frac{\exp \left[-\theta \times \frac{T C_{c a r}^{3}(l)}{T C^{3}}\right]}{\sum_{i=1}^{8} \exp \left[-\theta \times \frac{T C_{c a r}^{3}(l)}{T C^{3}}\right]} \\
& P_{c}^{4}(l)=\frac{\exp \left[-\theta \times \frac{T C_{c a r}^{4}(l)}{T C^{4}}\right]}{\sum_{i=1}^{9} \exp \left[-\theta \times \frac{T C_{c a r}^{4}(l)}{T C^{4}}\right]}
\end{aligned}
$$

where $T C_{c a r}^{1}(l), T C_{c a r}^{2}(l), T C_{c a r}^{3}(l)$, and $T C_{c a r}^{4}(l)$ are the travel costs for cars within the travel range enclosed by the arcs of $500 \mathrm{~m}$ to $1 \mathrm{~km}, 1-3 \mathrm{~km}, 3-6 \mathrm{~km}$, and above $6 \mathrm{~km}$ from the rail station, respectively; $\overline{T C}^{1}, \overline{T C}^{2}, \overline{T C}^{3}$, and $\overline{T C}^{4}$ are the average travel costs of all the travel chain modes within the corresponding travel range. A general model of the travel mode chain cost at different distances is established, and thus, the travel cost of the travel mode chain can be calculated. The travel cost can be converted into the travel structure, and the travel structure at different distances can be combined with the travel demand generated under the condition of mixed land use to calculate the number of incoming cars, thereby providing the basis for calculating parking demand. The relationship between the travel cost of the travel mode chain and the parking demand at different distances is established, thereby indirectly reflecting the concept of TOD.

\section{TOD Parking Demand Model in New Urban Areas}

The travel mode structure at different travel distances is analyzed, and the proportion of car trips is obtained. Subsequently, we focus on calculating the travel demand in the new urban area. Thus, the travel volume of cars can be calculated by combining the travel structure at different travel distances.

\subsection{Travel Demand}

In traditional travel demand forecasting, the travel production is divided into travel generation and travel attraction. The resident's travel purpose is divided into four types as follows: going to work, going to school, returning home, and flexible purposes. Then, the factors related to the travel production that affect the four travel purposes according to the property of land use in the 
community are determined [28]. However, urban land use is the source of urban transportation demand. Different land-use layouts, land-use properties, and land-use intensities correspond to different transportation demands. Moreover, travel production includes travel generation and travel attraction. The former is based on the socioeconomic characteristics of urban residents, and the latter is based on the form of land use. Then, the travel production is converted into travel distribution through the gravity model, and the travel demand (OD) can be obtained.

The forecasting methods of travel production mainly include the original unit method, the growth rate method, and the cluster analysis method [29]. The original unit method is adopted in this study. The two types of original unit methods include the individual original unit method that uses the average production per person of the residential or working population to conduct calculation, and the area unit method that uses the average production of unit office space or land space for different purposes to conduct prediction. In accordance with the product of the original unit of generation, the original unit of attraction and the attributes, such as population and area, the value of travel generation and travel attraction can be obtained. The calculation formula is as follows:

$$
O_{i}=b \times x_{i} \quad D_{j}=c \times x_{j}
$$

where $i$ and $j$ are the serial numbers of traffic districts; $x_{i}$ and $x_{j}$ are attribute variables, such as population, land-use type, and land area; $b$ is the number of unit travels for a certain travel purpose; $c$ is the number of unit attraction for a certain travel purpose; $O_{i}$ is the traffic generation of traffic district $i ; D_{j}$ is the attraction of traffic district $j$.

The gravity model method can describe the traffic travel behavior of urban residents effectively because it considers the attraction extent and attraction resistance factors among traffic districts. The travel production $O_{i}$ and $D_{j}$ obtained can be converted into travel demand OD by the gravity model method. The calculation formula is as follows:

$$
T_{i j}=k \times \frac{O_{i}^{\alpha} D_{j}^{\beta}}{R_{i j}^{\gamma}}
$$

where $T_{i j}$ is the traffic volume from travel district $i$ to traffic district $j ; R_{i j}$ is the travel distance from travel district $i$ to traffic district $j ; \alpha, \beta, \gamma$, and $k$ are the coefficients of the model.

\subsection{Parking Demand}

After obtaining the travel demand $T_{i j}$, through combining the travel demand and travel structure at different distances with the load carrying rate of cars, the number of incoming cars between each traffic district can be calculated. However, the number of incoming cars does not correspond to the parking demand, and it does not necessarily have to be fully satisfied. In this section, travel demand is converted into parking demand.

For a pure residential district, the parking demand should be equal to the incoming cars in the district. However, for traffic districts with mixed land use, such as TOD, the concept of parking sharing should be considered to reduce the parking demand. This method is different from the previous two types of mixed land, which use the minimum number of berths to conduct reduction and conversion. The parking demand of mixed land types should be divided into two parts, namely, the incoming cars of the land type, which mainly attract traffic volumes, and the outgoing cars by the land type, which mainly generate traffic volumes. In general, according to the sharing extent of the mixed land, only the parking attraction of land types, which mainly attract traffic volumes, is adjusted and reduced, and the rigid parking demand of land types that mainly generate traffic volumes is unadjusted. Thus, the formula for calculating the parking demand in ordinary traffic districts is as follows:

$$
Q_{i}=\frac{T_{i j} \times \alpha_{i j}}{c}
$$




$$
\begin{gathered}
S_{i}=\frac{T_{i j} \times \alpha_{i j} \times \bar{t}}{c \times \lambda} \\
P_{i}=\phi \times Q_{i}+\varphi \times S_{i} \\
P=\sum_{i=1}^{m} P_{i}
\end{gathered}
$$

where $P$ is the parking demand within $500 \mathrm{~m}$ of the rail station; $P_{i}$ is the parking demand of traffic district $i ; Q_{i}$ is the parking generation of traffic district $i$; $S_{i}$ is the parking attraction of traffic district $i$; $n$ is the number of traffic districts within $500 \mathrm{~m}$ of the rail station; $c$ is the average number of passengers carried by private cars; $\bar{t}$ is the average parking time; $\lambda$ is the parking turnover rate; $\phi$ and $\varphi$ are model coefficients, $\phi$ is set to 1 , and $\varphi \leq 1$. $\varphi$ reflects the extent of parking sharing on the mixed land.

By combining Formulas (29)-(32), we can obtain the parking demand within $500 \mathrm{~m}$ of the rail station, and the result is as follows:

$$
\begin{array}{r}
P=\sum_{i=1}^{m} \frac{\phi}{n}\left(T_{i j}^{1} \times P_{c}^{1}(l)+T_{i j}^{2} \times P_{c}^{2}(l)+T_{i j}^{3} \times P_{c}^{3}(l)+T_{i j}^{4} \times P_{c}^{4}(l)\right) \\
+\sum_{i=1}^{m} \frac{\varphi \times \bar{t}}{n \times a}\left(T_{i j}^{1} \times P_{c}^{1}(l)+T_{i j}^{2} \times P_{c}^{2}(l)+T_{i j}^{3} \times P_{c}^{3}(l)+T_{i j}^{4} \times P_{c}^{4}(l)\right)
\end{array}
$$

where $T_{i j^{\prime}}^{1}, T_{i j^{\prime}}^{2}, T_{i j}^{3}$, and $T_{i j}^{4}$ are the traffic districts within the area enclosed by arcs within the range of $500 \mathrm{~m}$ to $1 \mathrm{~km}, 1-3 \mathrm{~km}, 3-6 \mathrm{~km}$, and above $6 \mathrm{~km}$ of the rail station, respectively.

\section{Case Study of Binhai New City in Hangzhou Bay New Area}

\subsection{Background}

Ningbo Hangzhou Bay New District is located in the northernmost part of Ningbo City on the south bank of the Hangzhou Bay Bridge. It is located at the geometric center of four major cities including Shanghai, Suzhou, Hangzhou, and Ningbo; it has a superior geographical position. Hangzhou Bay New Area is in the initial stage of urban living area development where the start-up area is in the planning stage. It is an undeveloped "green land." The travel mode is not yet formed; thus, it cannot fully satisfy the development conditions for implementing the TOD mode.

The selected Binhai New City starting block used for the pilot TOD exploitation and construction by Ningbo Hangzhou Bay New District Management Committee covers the Luzhongwan River in the east, Shitangheng River in the south, Zhi River in the west, and Shiyitangheng River in the north. The land area is approximately 12.8 square kilometers. The location of Binhai New City and its start-up area can be found in Figure 2. Ningbo Hangzhou Bay Binhai New City takes "travel pedestrianization, concept internationalization, production urbanization, and implementation feasible" as the development concept, actively strives to be China's model city in the 21st century authenticated by the Ministry of Housing and Urban-Rural Development, and is a leading example of TOD exploitation in domestic cities [30]. Different from other cities in China that have already applied the TOD concept to planning, the Hangzhou Bay New Area arranges rail transit and then conducts land development, avoiding the embarrassing situation of the "ghost city" in the planning landing stage, such as Kunming Chenggong New Area [31,32]. 


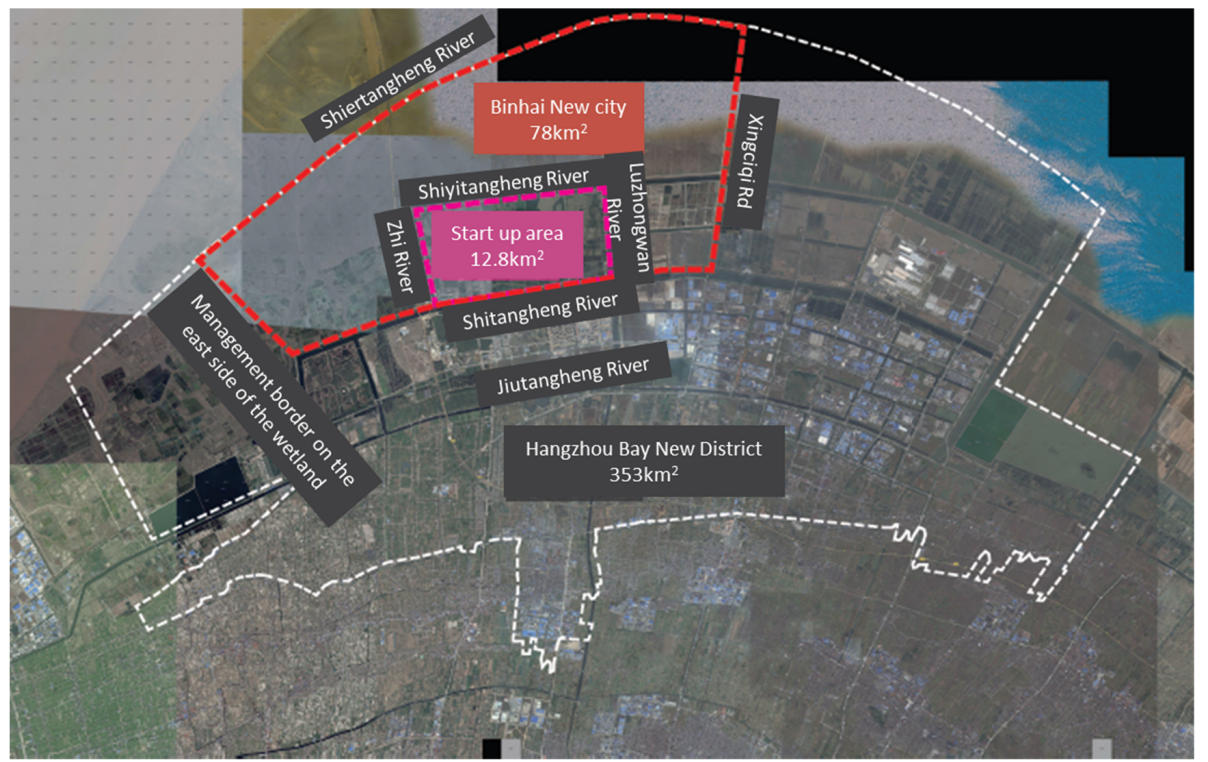

Figure 2. Location map of Binhai New City and start-up area.

In terms of transportation planning, Binhai New City is committed to creating a low-carbon transportation system that integrates safe and comfortable pedestrian transportation, friendly bicycle transportation, and convenient public transportation. For pedestrian transportation, a safe and comfortable pedestrian city through a hierarchical road network system, reasonable traffic calming, high-quality street space, and safe street crossings was built, as shown in Figure 3. For bicycle transportation, a special bicycle loop and a complete public bicycle rental network were built to encourage bicycle travel, as shown in Figure 4. For public transportation, trams were selected as the backbone public transportation method in the planning area, combined with conventional public transportation and auxiliary public transportation to form the public transportation system in the planning area. At the same time, to put forward the following requirements for public transportation systems, such as rail transit, a multi-mode public transportation method was built, and a convenient public transportation network was created. Thus, transfer is convenient among rail transit, bus, and bicycle, and the entire region is protected with rail transit and bus networks. The layouts of the rail transit in Binhai New City and the long-term rail transit in Hangzhou Bay New Area are shown in Figure 5.

In terms of land planning, Ningbo Hangzhou Bay New District took the TOD development concept as the guide, deepened the land layout, implemented the blueprint for the integration of industry and city, and proposed four types of TOD, namely, city center TOD, tourism TOD, community TOD, and headquarter park TOD around the tram line, as shown in Figure 6.

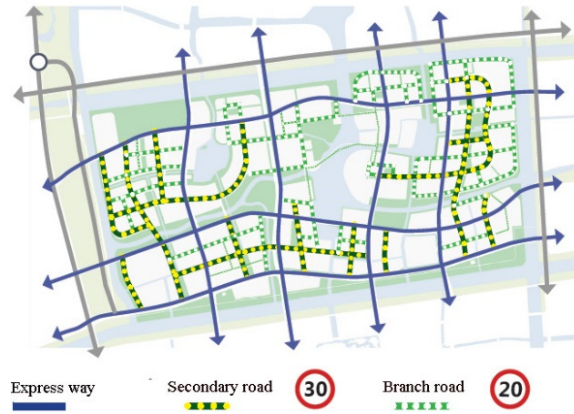

(a)

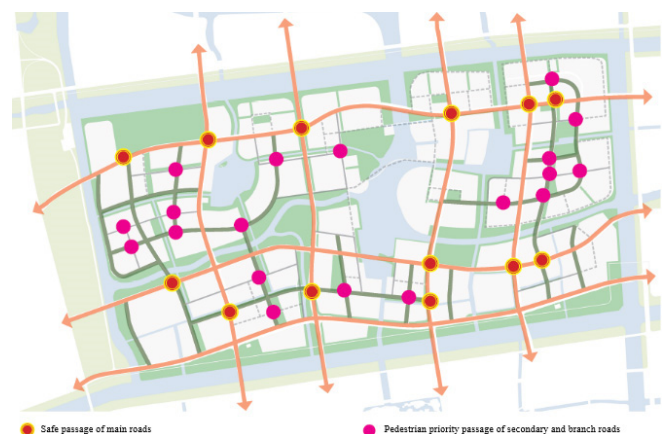

(b)

Figure 3. (a) Reasonable traffic calming layout plan; (b) Safe street crossing layout plan. 


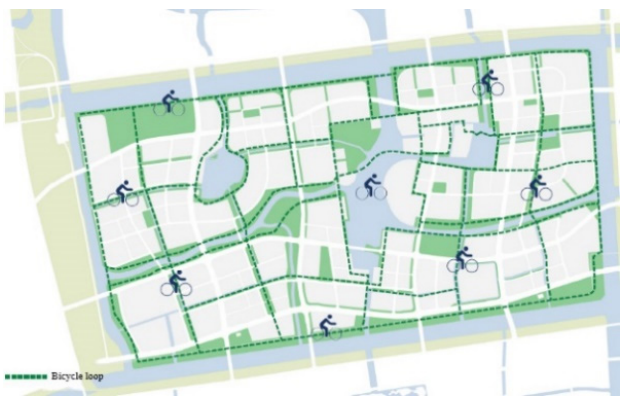

(a)

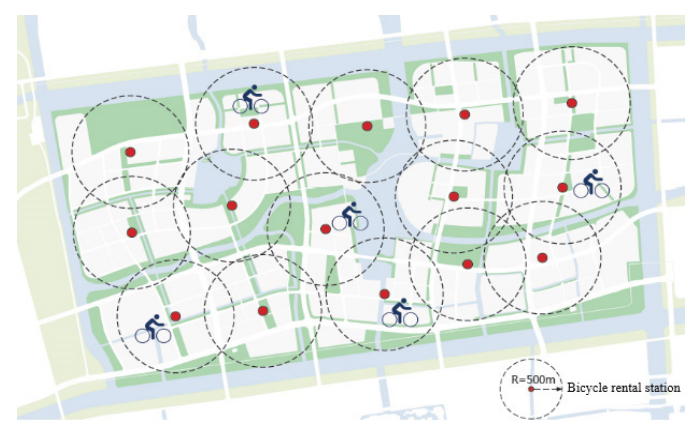

(b)

Figure 4. (a) Layout of the bicycle loop; (b) Layout of the safe street crossing.

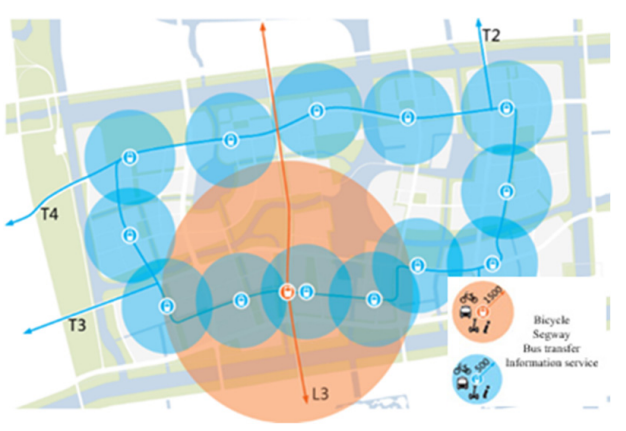

(a)

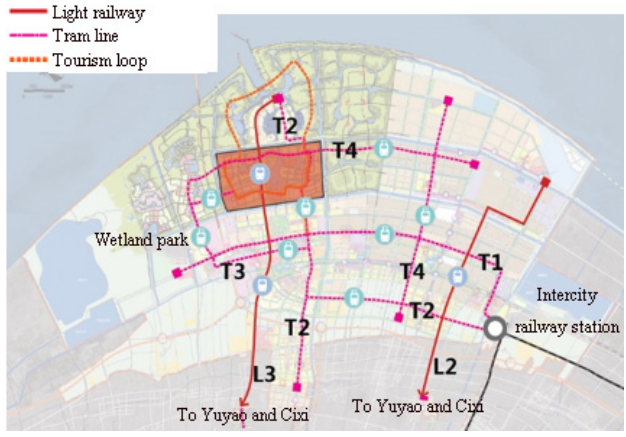

(b)

Figure 5. (a) Layout of the rail transit in Binhai New City; (b) Layout of the long-term rail transit in Hangzhou Bay New Area.

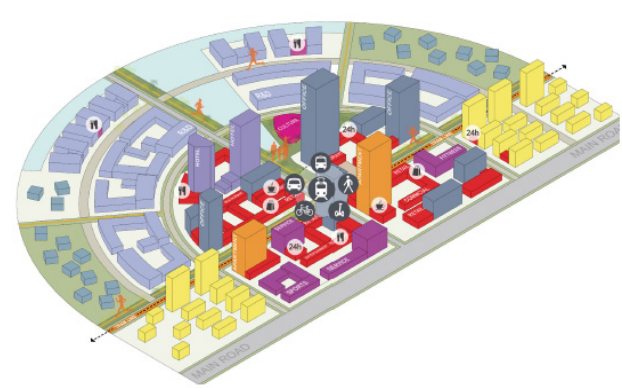

(a)

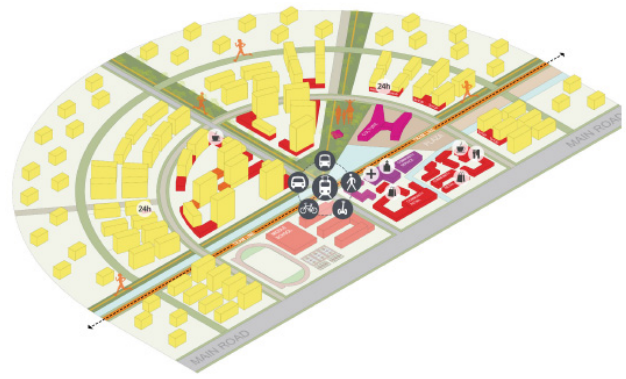

(c)

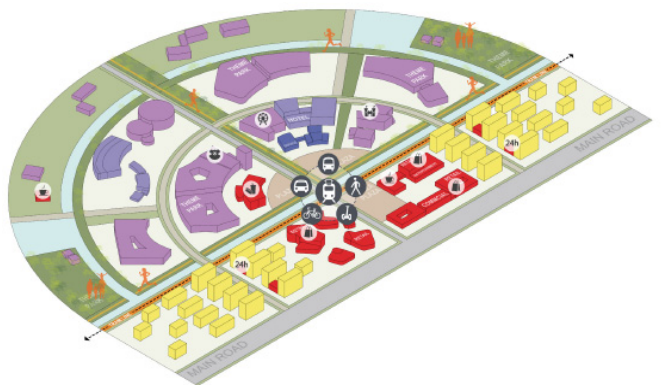

(b)

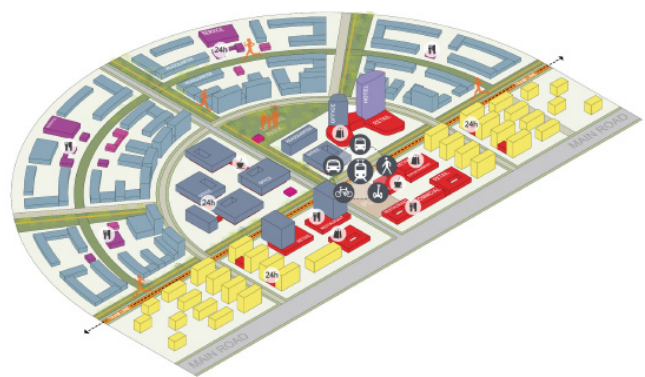

(d)

Figure 6. (a) City center TOD; (b) Tourism TOD; (c) Community TOD; (d) Headquarter park TOD. 


\subsection{Parking Demand}

\subsubsection{Analysis on Travel Structure and Travel Cost}

On the basis of the model established in the previous chapter, the travel costs of all the single-way travel mode were calculated, and then the travel structures at different travel distances in the single-way travel mode were computed using the logit model, as shown in Figures 7 and 8:

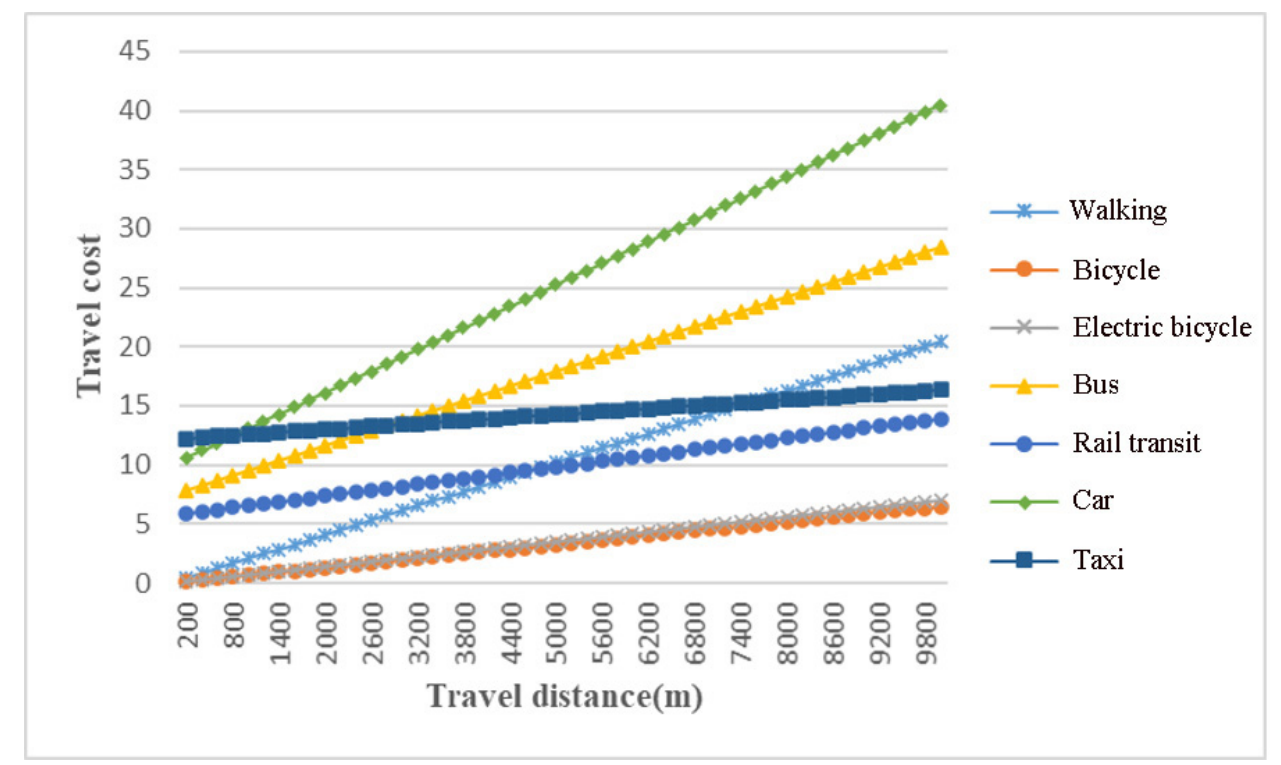

Figure 7. Travel costs for different travel modes.

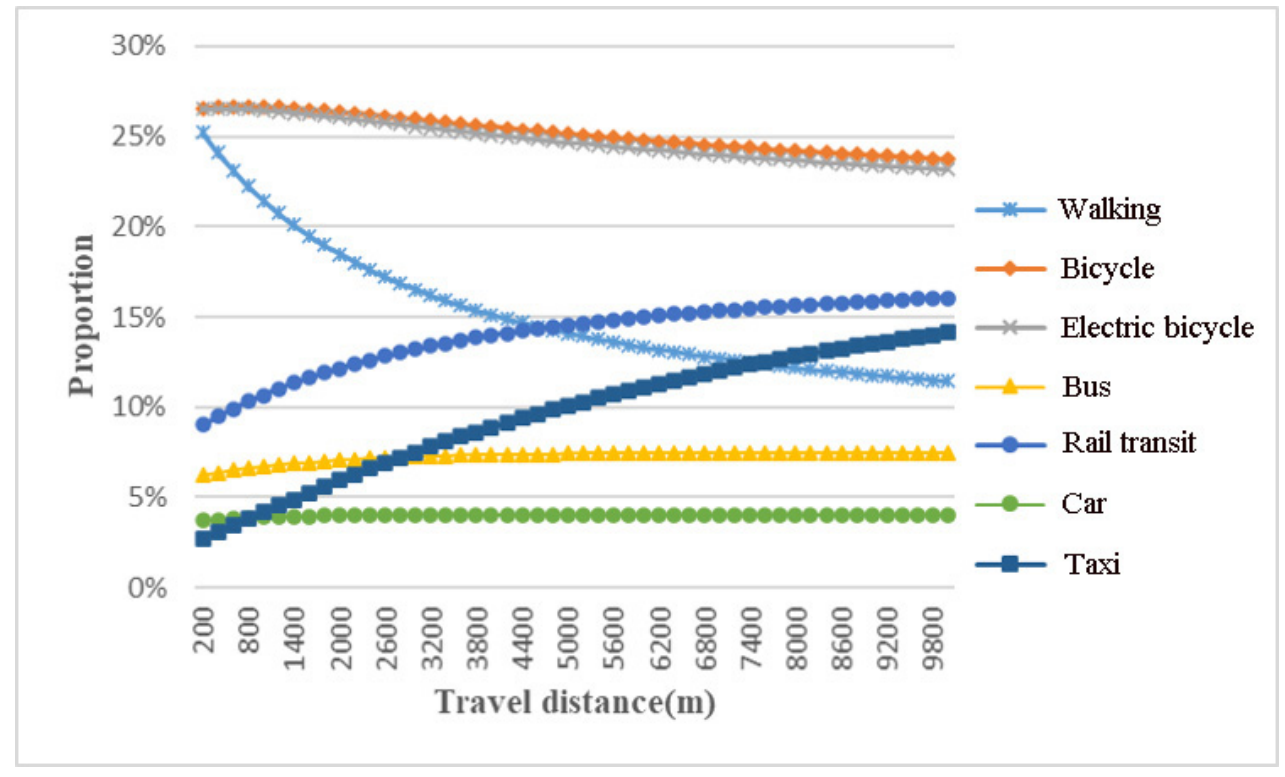

Figure 8. Travel structures at different travel distances.

When all travelers traveled in the single-way travel mode, as the travel distance changed, some travel modes actually experienced a sharp increase in travel costs or abnormalities. Therefore, when calculating the travel structure through the travel cost to find the parking demand, we considered different travel distances in the travel chain to quantify the travel cost. In accordance with the composition of the travel chain cost in Section 4, the travel time costs for each travel chain mode were calculated, as is shown in Table 4. 
Table 4. Travel time costs for each travel chain mode.

\begin{tabular}{ccc}
\hline Travel Mode & Travel Time Cost (yuan) & Travel Distance Limit \\
\hline Walking & 2.04 & $l \leq 3 \mathrm{~km}$ \\
Bicycle & $0.65 l$ & $l \leq 6 \mathrm{~km}$ \\
Bus & Off peak: $0.56 l ;$ Peak: $0.93 l$ & $l \geq 500 \mathrm{~m}$ \\
Rail transit & $0.25 l$ & $l \geq 1 \mathrm{~km}$ \\
Car & Off peak: $0.31 l ;$ Peak: $0.36 l$ & $l \geq 500 \mathrm{~m}$ \\
Taxi & Off peak: $0.31 l ;$ Peak: $0.36 l$ & $l \geq 500 \mathrm{~m}$ \\
Bicycle + rail transit & $0.90 l$ & $l \geq 3 \mathrm{~km}$ \\
Bicycle + bus & $1.58 l$ & $l \geq 3 \mathrm{~km}$ \\
Car + rail transit & $0.52 l$ & $l \geq 6 \mathrm{~km}$ \\
Taxi+ rail transit & $0.52 l$ & $l \geq 6 \mathrm{~km}$ \\
\hline
\end{tabular}

When the travel time costs for each travel mode were obtained, the total cost of the travel chain was calculated. Thus, the travel structure at different distances was derived through the logit model, and the results are shown in Table 5 .

Table 5. Travel structures of each travel chain mode at different distances.

\begin{tabular}{|c|c|c|c|c|c|c|}
\hline Travel Structure & $\begin{array}{c}\text { Travel Range } \\
\text { Travel Distance }\end{array}$ & $\begin{array}{c}0-500 \mathrm{~m} \\
300 \mathrm{~m}\end{array}$ & $\begin{array}{c}0.5-1 \mathrm{~km} \\
800 \mathrm{~m}\end{array}$ & $\begin{array}{c}1-3 \mathrm{~km} \\
2 \mathrm{~km}\end{array}$ & $\begin{array}{c}3-6 \mathrm{~km} \\
5 \mathrm{~km}\end{array}$ & $\begin{array}{l}\text { Above } 6 \mathrm{~km} \\
10 \mathrm{~km}\end{array}$ \\
\hline \multirow{11}{*}{ Travel chain mode } & Walking & $26.24 \%$ & $33.67 \%$ & $24.30 \%$ & & \\
\hline & Bicycle & $73.76 \%$ & $39.26 \%$ & $33.21 \%$ & $24.61 \%$ & \\
\hline & Bus & & $11.99 \%$ & $10.43 \%$ & $8.87 \%$ & $8.71 \%$ \\
\hline & Car & & $7.56 \%$ & $6.31 \%$ & $5.33 \%$ & $5.25 \%$ \\
\hline & Taxi & & $7.51 \%$ & $8.94 \%$ & $11.45 \%$ & $14.44 \%$ \\
\hline & Rail transit & & & $16.82 \%$ & $15.59 \%$ & $15.99 \%$ \\
\hline & $\begin{array}{l}\text { Bicycle }+ \text { rail } \\
\text { transit }\end{array}$ & & & & $15.81 \%$ & $16.13 \%$ \\
\hline & Bus + rail transit & & & & $8.66 \%$ & $11.22 \%$ \\
\hline & Bicycle + bus & & & & $9.67 \%$ & $9.17 \%$ \\
\hline & Car + rail transit & & & & & $8.72 \%$ \\
\hline & Taxi+ rail transit & & & & & $10.36 \%$ \\
\hline \multicolumn{2}{|c|}{ Total } & 1 & 1 & 1 & 1 & 1 \\
\hline
\end{tabular}

\subsubsection{Analysis of Parking Demand at Rail Stations}

A CAD software was used to conduct the macro-traffic simulation modeling. Ningbo Hangzhou Bay New District was divided into 110 traffic communities, including seven peripheral traffic communities, as shown in Figure 9. In addition, the Binhai New City was divided into 15 traffic districts, as shown in Figure 10. The division of the traffic districts was mainly based on the boundaries of neighborhoods and the urban rivers.

Here, we chose a station of the tram T2 line for case analysis, and its type is community TOD. A neighborhood center is set up near the station to satisfy the daily needs of the community for business and public affairs. At the same time, the functions around the station are mixed. The development intensity of the land close to the station is relatively high, and the development intensity of the land far away from the station is relatively low. In addition, the station has high traffic accessibility. In addition to the connection of trams, the station can be easily reached by walking, bicycle, and bus. Moreover, public parking lots are set up around the station. The overall public transport layout around the rail station is shown in Figure 11.

Here, we selected the range of $500 \mathrm{~m}$ around the rail station to calculate the parking demand. The affected area of this site included the original traffic districts 5182 and 5184. These traffic districts were refined into six and 18 traffic districts, of which 12 new traffic districts were within $500 \mathrm{~m}$ from the rail station, namely, 5301, 5302, 5303, 5304, 5307, 5308, 5309, 5310, 5316, 5319, 5320, and 5321, as shown in Figures 12 and 13. The land-use types and floor area ratios of each traffic district are shown in Table 6. 


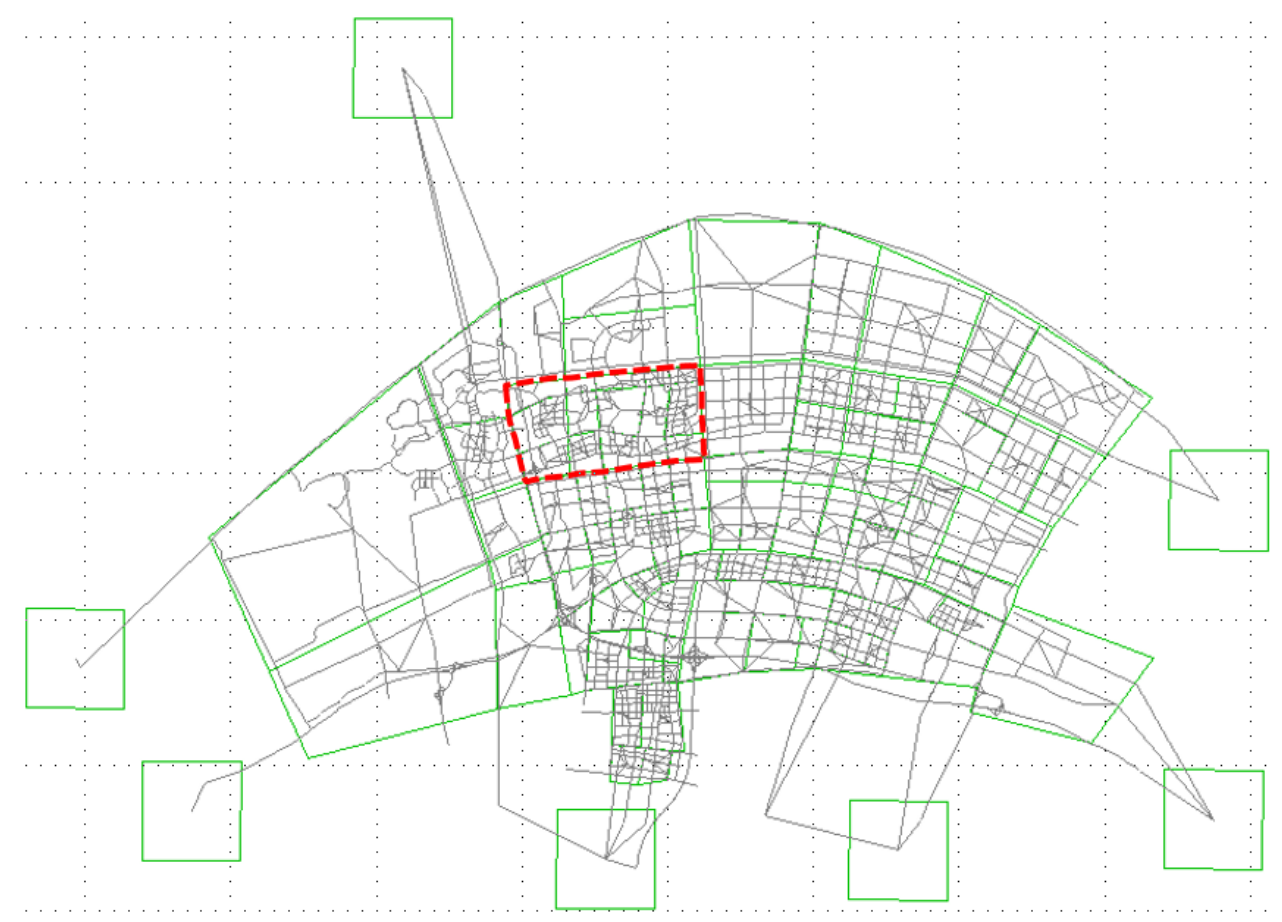

Figure 9. Macro-traffic simulation modeling of Ningbo Hangzhou Bay New District.

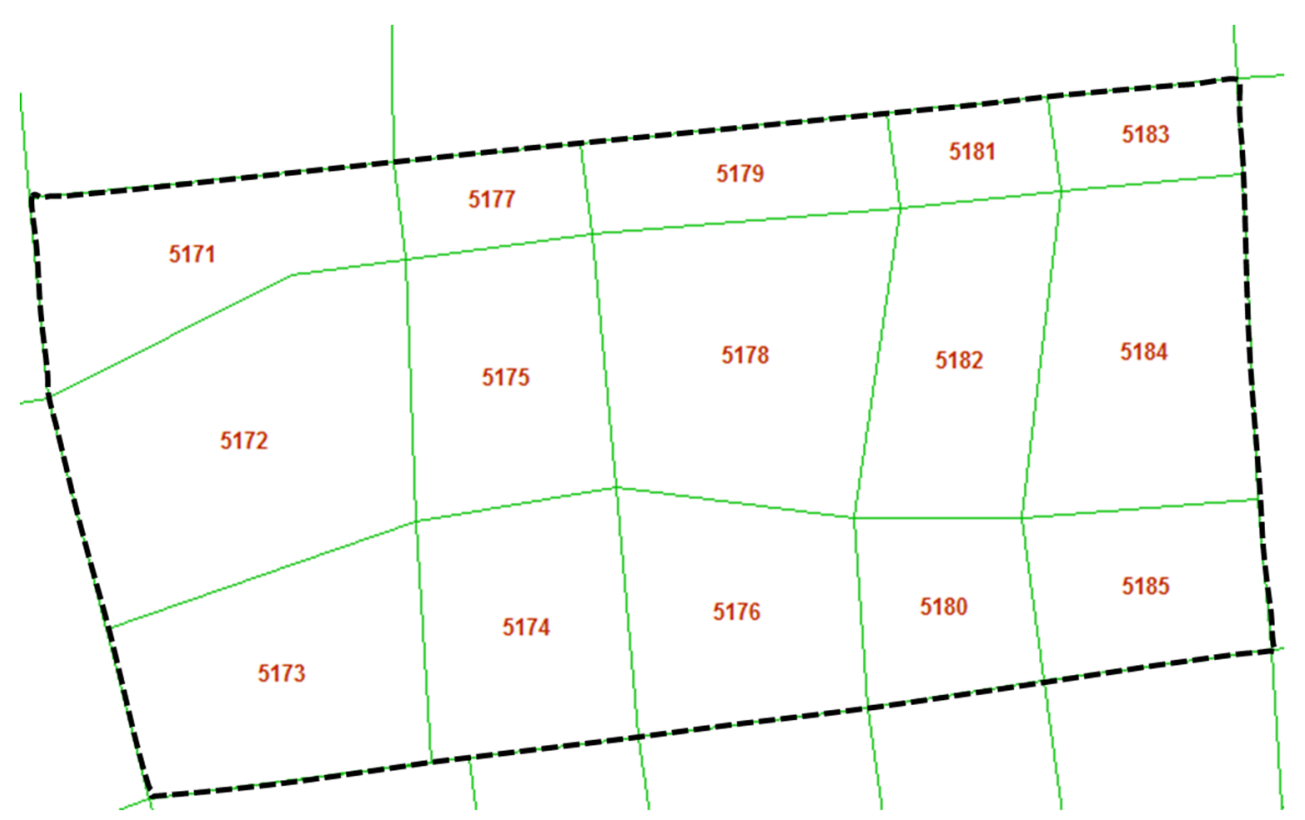

Figure 10. Macro-traffic simulation modeling of the Binhai New City. 


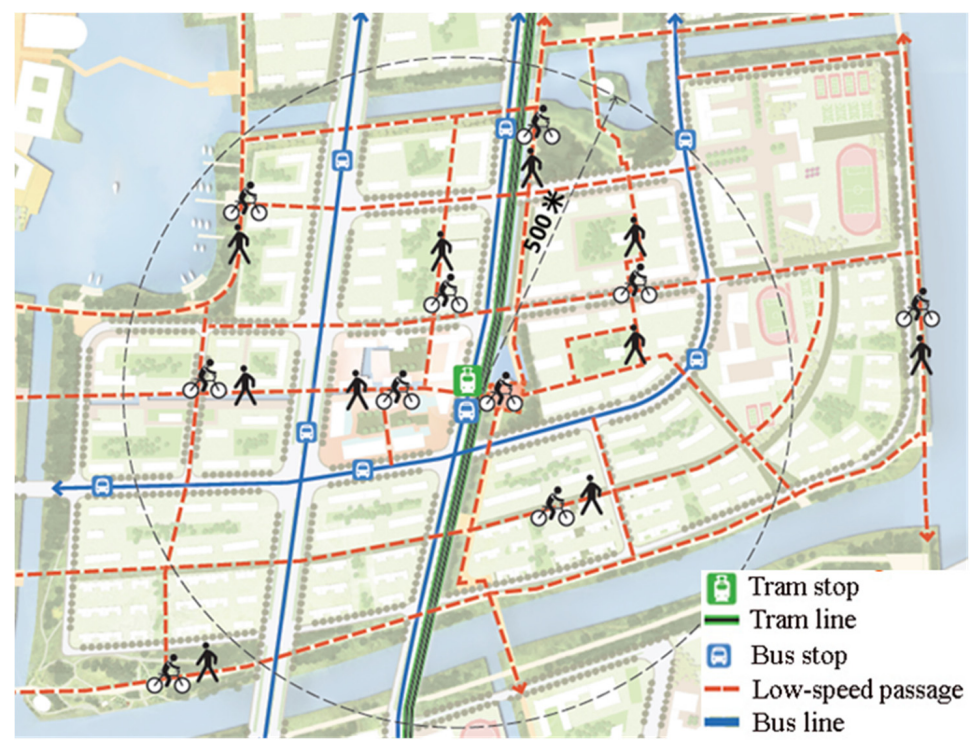

Figure 11. Public transport layout around the rail station.

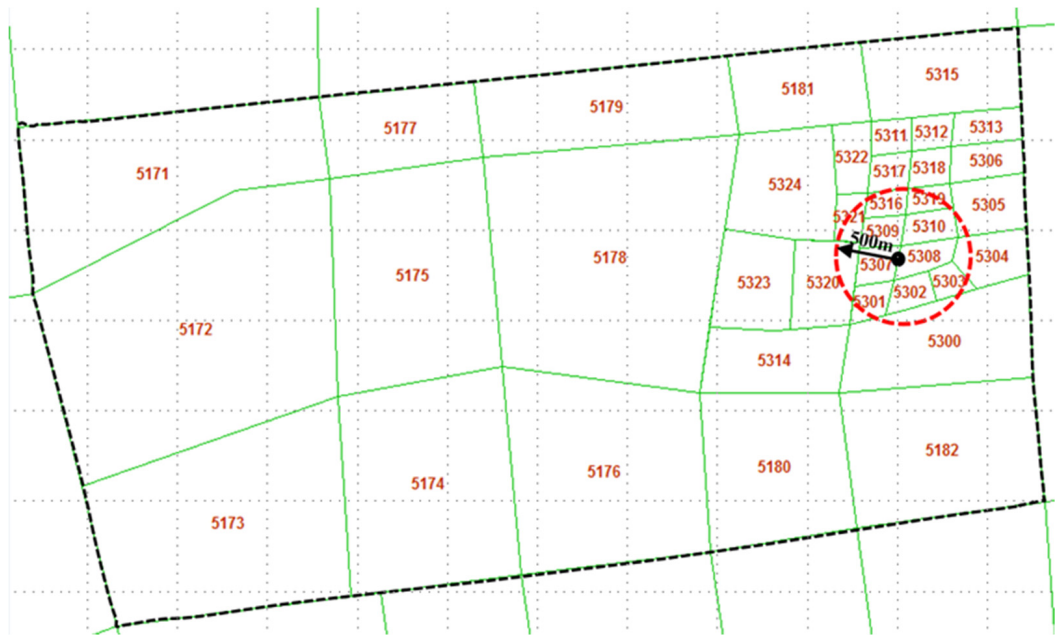

Figure 12. Traffic districts within $500 \mathrm{~m}$ of the rail station.

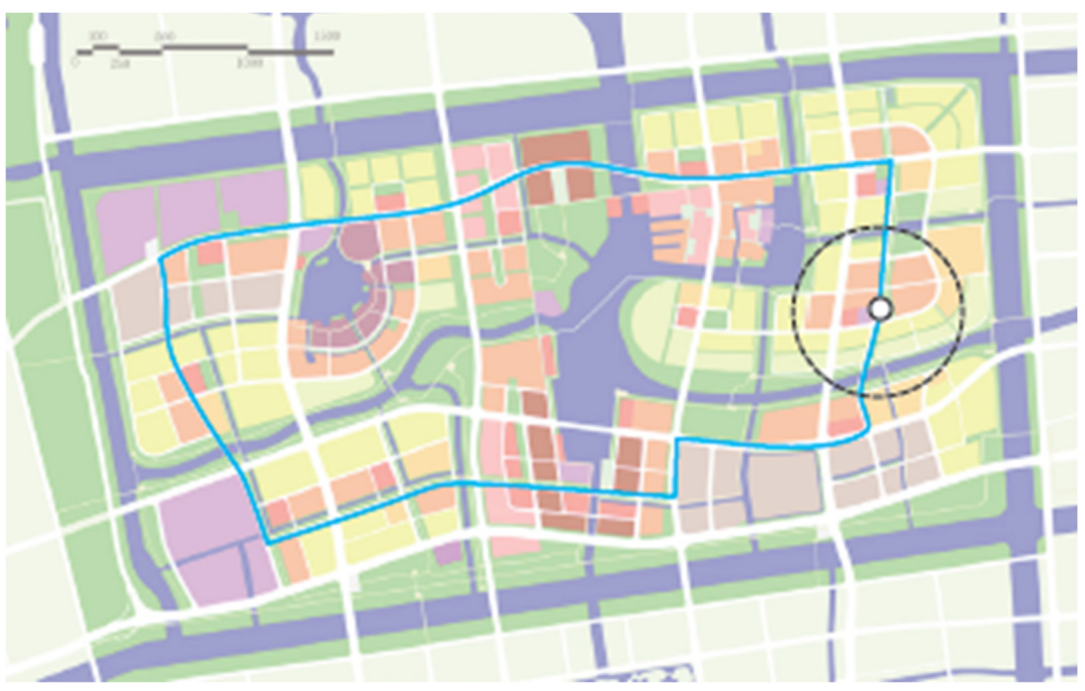

Figure 13. Land-use plan of the Binhai New City in Hangzhou Bay New Area. 
Table 6. Land-use types and floor area ratios of each traffic district within $500 \mathrm{~m}$ of the rail station.

\begin{tabular}{|c|c|c|c|c|c|c|c|c|}
\hline ID & Land Use Type & Residence & Floor Area Ratio & Commerce & $\begin{array}{l}\text { Floor } \\
\text { Area } \\
\text { Ratio }\end{array}$ & Office & $\begin{array}{l}\text { Floor } \\
\text { Area } \\
\text { Ratio }\end{array}$ & $\begin{array}{c}\text { Total } \\
\text { Construction } \\
\text { Area }\end{array}$ \\
\hline 5316 & Residence & 20,144 & 1.1 & -1 & - & - & - & 20,144 \\
\hline 5319 & Residence & 29,013 & 1.1 & - & - & - & - & 29,013 \\
\hline 5310 & $\begin{array}{c}\text { Residence }+ \text { Commerce } \\
+ \text { office }\end{array}$ & 27,817 & 1.5 & 10,000 & 2 & 4605 & 2 & 42,423 \\
\hline 5309 & Residence + Commerce & 20,001 & 1.5 & 12,088 & 2 & & & 32,089 \\
\hline 5307 & Commerce + office & - & - & 20,000 & 2.8 & 16,797 & 2.8 & 36,797 \\
\hline 5308 & Commerce + office & 20,000 & 2 & 15,337 & 2.8 & 12,127 & 2.8 & 47,464 \\
\hline 5304 & Residence & 75,686 & 0.8 & - & - & - & - & 75,686 \\
\hline 5303 & Residence & 35,185 & 1.2 & - & - & - & - & 35,185 \\
\hline 5302 & Residence + Commerce & 40,246 & 1.4 & 6133 & 2 & - & - & 46,379 \\
\hline 5301 & Residence + Commerce & 24,970 & 1.4 & 10,000 & 2 & - & - & 34,970 \\
\hline 5320 & Residence & 124,337 & 0.9 & - & - & - & - & 124,337 \\
\hline \multirow[t]{2}{*}{5321} & Residence & 26,396 & 1.2 & - & - & - & - & 26,396 \\
\hline & Total & 443,797 & & 73,558 & & 33,530 & & 550,884 \\
\hline
\end{tabular}

On the basis of the macroscopic traffic simulation model of Binhai New City established previously by the CAD software, after traffic generation using the original unit method and traffic distribution using the gravity model method, the travel demands of each traffic district within $500 \mathrm{~m}$ of the rail station were calculated, as shown in Table 7.

Table 7. Travel demands of each traffic district within $500 \mathrm{~m}$ of the rail station.

\begin{tabular}{cccccccccccccc}
\hline \multicolumn{11}{c}{ Within 500 Meters of the Rail Station } \\
\hline $\begin{array}{c}\text { Traffic District } \\
\begin{array}{l}\text { Travel demand } \\
\text { (person-time) }\end{array}\end{array}$ & 5301 & 5302 & 5303 & 5304 & 5307 & 5308 & 5309 & 5310 & 5316 & 5319 & 5320 & 5321 \\
\hline Total & 6500 & 7863 & 9950 & 11,119 & 12,200 & 6684 & 9111 & 3973 & 5368 & 14,115 & 5093 \\
\hline
\end{tabular}

The travel demands of cars at different travel distances was calculated by combining with the travel structure at different travel distances in Binhai New City in the previous section. The average number of passengers carried by a private car was 1.5, and the turnover rate was determined by analogy. Then, $\varphi$ was determined in accordance with the extent of sharing among different land-use types. The average value of $\varphi$ was 0.89 . The parking demands of each traffic district were obtained using Formula (33), as shown in Table 8.

Table 8. Number of parking spaces within $500 \mathrm{~m}$ of a rail station.

\begin{tabular}{lccccccccccccc}
\hline \multicolumn{11}{c}{ Within $\mathbf{5 0 0}$ Meters of the Rail Station } \\
\hline Traffic District & 5301 & 5302 & 5303 & 5304 & 5307 & 5308 & 5309 & 5310 & 5316 & 5319 & 5320 & 5321 \\
Parking spaces & 406 & 406 & 438 & 556 & 621 & 685 & 379 & 513 & 221 & 299 & 789 & 284 \\
\hline \multicolumn{110}{c}{ Total } & 1107 \\
\hline
\end{tabular}

\subsubsection{Parking Demand Accounting Under Standardized Conditions}

The three land-use types were residence, office, and commerce, which corresponded to the residential commercial housing, the core area of office business, and the core area of commercial comprehensive business in the city standard, respectively. Their motor vehicle parking indicators were 1.0, 0.7 , and 0.7 (the measurement unit is every 100 square meters of building area), and then the combination of office and residence was reduced. The parking spaces were calculated for 12 traffic districts involved within $500 \mathrm{~m}$ of the rail station, and the results are shown in Table 9.

The parking demand model for TOD in new urban areas calculated the total parking demand within $500 \mathrm{~m}$ of the rail station to 5597 berths, and the result of the standard method calculation was 6802 berths. The former was $17.71 \%$ less than the latter, and the results of the TOD method in each traffic district were lower than those of the standard method, as shown in Figure 14. 
Table 9. Number of parking spaces within $500 \mathrm{~m}$ of a rail station (Standard method).

\begin{tabular}{|c|c|c|c|c|c|c|c|c|c|c|c|c|}
\hline \multicolumn{13}{|c|}{ Within 500 Meters of the Rail Station } \\
\hline Traffic District & 5301 & 5302 & 5303 & 5304 & 5307 & 5308 & 5309 & 5310 & 5316 & 5319 & 5320 & 5321 \\
\hline Parking spaces & 490 & 649 & 422 & 605 & 721 & 867 & 469 & 602 & 222 & 319 & 1119 & 317 \\
\hline
\end{tabular}

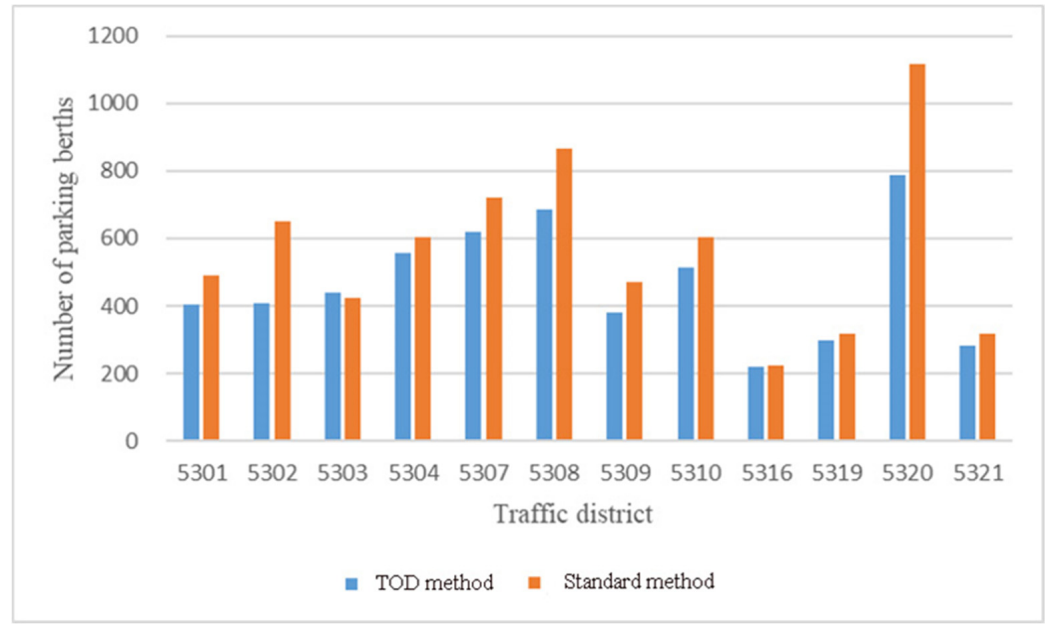

Figure 14. Comparison of parking berths between the two methods

\section{Conclusions}

This study focuses on investigating and establishing the parking demand model for TOD in new urban areas. On the basis of the travel distance around the rail station, the travel costs for each travel mode were analyzed, and the travel chain cost structures at different distances were established. Through the logit model, the relationship between the travel chain cost and the travel structure was connected. Then, a travel structure measurement model at different distances was established. Finally, the relationship between travel demand and parking demand was analyzed, the parking turnover rate was considered, and a parking demand model for TOD-oriented new urban areas was established.

In addition, the established model was applied to the case of the Binhai New City in Hangzhou Bay New District, Ningbo, to quantify the parking demand in the TOD-oriented new urban areas. The results were compared with those of traditional standard methods and appeared gratifying. The conclusions are summarized as follows:

1. Among the seven single-way travel modes, the travel proportions of car and bus are the most insensitive to travel distance, while the proportion of walking sharply decreases as the travel distance rises.

2. When travel distance goes beyond $2 \mathrm{~km}$, travel chains involving two travel modes become more adopted by residents, among which the combination of bicycle and rail transit are the most popular.

3. In the TOD-oriented new urban area, travel demand by cars is discouraged and residents are more willing to travel in greener ways.

4. Parking demand in the TOD-oriented new urban area is reduced by $17.71 \%$ compared with that of the standard method, which helps to alleviate parking pressure in the area.

5. In terms of urban sustainability, the mixed land use resulting from TOD can apparently reduce the parking demand in the neighborhood, making the land-use pattern more effective. Meanwhile, the travel structure of the residents influenced by the TOD mode turns out to be more green and low carbon, which is in line with the sustainable development strategy. 
In this study, we expounded the role of TOD in reducing parking demand and revealed the advantages of the TOD mode in reducing parking demand. Following the work presented in this paper, we recognize some areas that may be explored in future research.

1. External cost can be taken into consideration when it involves government policy management in further researches.

2. Travel chains made up of three or more travel modes can be considered in order to improve the model to reflect the situations in real life better.

3. More case studies involving the other three types of TOD can be conducted to reinforce the universality and authority that the TOD mode is effective in reducing parking demand.

Author Contributions: The authors confirm contributions to the paper as follows: conceptualization, Z.M.; formal analysis, L.K.; methodology, L.K. and W.Z.; investigation, L.K. All authors reviewed the results and approved the final version of the manuscript.

Funding: This research was funded by the National Key Research and Development Program of China (No. 2019YFB1600300).

Acknowledgments: The authors thank Mr. Zhou Chao of Hangzhou Bay New Area for his support on the data.

Conflicts of Interest: The authors declare no conflict of interest.

\section{References}

1. Song, Y. What does 200 million private car ownership mean? China Environment News, 15 January 2020; p. 003.

2. Guo, Q. China will invest about 3 trillion yuan in building parking lots. China Auto Parts Mark. 2015, 5, 16.

3. Zhang, C.; Zhang, X.; Ye, H.; Wei, M.; Ning, X. An Efficient Parking Solution: A Cam-Linkage Double-Parallelogram Mechanism Based 1-Degrees of Freedom Stack Parking System. J. Mech. Robot. 2019, 11. [CrossRef]

4. Mei, Z.; Feng, C.; Ding, W.; Zhang, L.; Wang, D. Better lucky than rich? Comparative analysis of parking reservation and parking charge. Transp. Policy 2019, 75, 47-56. [CrossRef]

5. Calthorpe, P. The Next American Metropolis-Ecology, Community, and the American Dream; Princeton Architectural Press: New York, NY, USA, 1993.

6. Nasri, A.; Zhang, L. The analysis of transit-oriented development (TOD) in Washington, D.C. and Baltimore metropolitan areas. Transp. Policy 2014, 32, 172-179. [CrossRef]

7. Lu, Y.C. Research on Parking Demand of the TOD Community. Master's Thesis, Southeast University, Nanjing, China, 2006.

8. Xu, X.C. City Road and Traffic Planning; China Architecture \& Building Press: Beijing, China, 2007.

9. Li, J.; Huang, H. Effects of transit-oriented development (TOD) on housing prices: A case study in Wuhan, China. Res. Transp. Econ. 2020, 80, 100813. [CrossRef]

10. Kong, W.; Pojani, D. Transit-oriented street design in Beijing. J. Urban Des. 2017, 22, 1-23. [CrossRef]

11. Chen, F.; Wu, J.; Chen, X.; Wang, J. Vehicle kilometers traveled reduction impacts of Transit-Oriented Development: Evidence from Shanghai City. Transp. Res. Part D Transp. Environ. 2017, 55, 227-245. [CrossRef]

12. Lyu, G.; Bertolini, L.; Pfeffer, K. Is Labour Productivity Higher in Transit Oriented Development Areas? A Study of Beijing. Tijdschr. Econ. Soc. Geogr. 2020, 111, 652-670. [CrossRef]

13. Xu, W.A.; Guthrie, A.; Fan, Y.; Li, Y. Transit-oriented development: Literature review and evaluation of TOD potential across 50 Chinese cities. J. Transp. Land Use 2017, 10, 10. [CrossRef]

14. Nyunt, K.T.K.; Wongchavalidkul, N. Evaluation of Relationships between Ridership Demand and Transit-Oriented Development (TOD) Indicators Focused on Land Use Density, Diversity, and Accessibility: A Case Study of Existing Metro Stations in Bangkok. Urban Rail Transit 2020, 6, 56-70. [CrossRef]

15. Fu, Z. Commercial surge along the subway. Beijing Real Estate 2009, 5, $23-25$.

16. Huang, W.; Wey, W.-M. Green Urbanism Embedded in TOD for Urban Built Environment Planning and Design. Sustainability 2019, 11, 5293. [CrossRef]

17. He, C. Research and Application of Urban Parking Planning; China Architecture \& Building Press: Beijing, China, 2006.

18. Tan, Y.; Xiang, Q.; Gao, Y.; Chen, Y. Solving urban parking problems through unsubsidized operation. Urban Transp. China 2014, 1, 18-22. 
19. Nasri, A.; Carrion, C.; Zhang, L.; Baghaei, B. Using propensity score matching technique to address self-selection in transit-oriented development (TOD) areas. Transportation 2018, 47, 359-371. [CrossRef]

20. Ye, Y. Study on the Method of Travel Mode Chaining Cost. Master's Thesis, Zhejiang University, Hangzhou, China, 2015.

21. Hu, Y.; Gao, T. Study on the methods of quantifying the trip costs of urban traffic modes. Urban Public Transp. $2005,8,27-30$.

22. Gao, T. The Quantization Study of Trip Cost about Urban Different Trip Ways. Master's Thesis, Northeast Forestry University, Harbin, China, 2006.

23. Zong, F.; Juan, Z.; Zhang, H.; Jia, H. Calculation and application of value of travel time. J. Transp. Syst. Eng. Inf. Technol. 2009, 9, 114-119.

24. Zhou, G. Study on the structure of urban passenger transport system. Railw. Transp. Econ. 2012, 34, 50-55.

25. Tang, X.; Wang, W.; Cheng, L. Travel time reliability assessment for traffic networks. China Civil Eng. J. 2007, 40, 84-88, 110.

26. Gwilliam, K.M. The value of time in economic evaluation of transport projects: Lessons from recent research. In Proceedings of the Value of Time Seminar, London, UK, 29-30 October 1996.

27. Yue, Y.; Han, J.; Wang, S.; Liu, X. Integrated Train Timetabling and Rolling Stock Scheduling Model Based on Time-Dependent Demand for Urban Rail Transit. Comput. Civ. Infrastruct. Eng. 2017, 32, 856-873. [CrossRef]

28. Wang, W.; Guo, X.C. Traffic Engineering, 2nd ed.; Southeast University Press: Nanjing, China, 2011.

29. Shao, C.F. Principles of Traffic Planning; China Railway Publishing House: Beijing, China, 2014.

30. Astibon Architectural Design Consulting (Shanghai) Co., Ltd. Conceptual Urban Design for the Launch Block of Ningbo Hangzhou Bay Binhai New City; Astibon Architectural Design Consulting (Shanghai) Co., Ltd.: Shanghai, China, 2016.

31. Institute of Traffic Engineering, Zhejiang University. Special Planning for Road Traffic System in Binhai New City, Hangzhou Bay New District, Ningbo; Institute of Traffic Engineering, Zhejiang University: Hangzhou, China, 2016.

32. Jiang, Y.; Mohabir, N.; Ma, R.; Zhu, P. Sorting through Neoliberal Variations of Ghost Cities in China. Land Use Policy 2017, 69, 445-453. [CrossRef]

Publisher's Note: MDPI stays neutral with regard to jurisdictional claims in published maps and institutional affiliations.

(C) 2020 by the authors. Licensee MDPI, Basel, Switzerland. This article is an open access article distributed under the terms and conditions of the Creative Commons Attribution (CC BY) license (http://creativecommons.org/licenses/by/4.0/). 